\title{
An evaluation of Jacob's method for the interpretation of pumping tests in heterogeneous formations
}

\author{
Peter M. Meier, Jesús Carrera, and Xavier Sánchez-Vila \\ Departament Enginyeria del Terreny i Cartogràfica, ETS Enginyers de Camins, Canals i Ports de Barcelona \\ Universitat Politècnica de Catalunya, Barcelona, Spain
}

\begin{abstract}
Most pumping tests are interpreted using the classical Theis assumption of large-scale homogeneity with various corrections to account for early time behavior of drawdown curves. When drawdowns are plotted versus log time, late time data often delineate a straight line, which is consistent with Jacob's approximation of Theis' solution but may seem surprising in view of the heterogeneity of natural media. The aim of our work is to show that Jacob's method leads to a good approximation of the effective transmissivity of heterogeneous media when constrained to late time data. A review of several multiwell pumping tests demonstrates that when drawdown curves from each observation well are interpreted separately, they produce very similar transmissivity $T$ estimates. However, the corresponding estimates for storativity span a broad range. This behavior is verified numerically for several models of formation heterogeneity. A very significant finding of the numerical investigation is that $T$ values estimated using simulated drawdown from individual observation wells are all very close to the effective $T$ value for parallel flow. This was observed even in nonmultiGaussian $T$ fields, where high $T$ zones are well connected and where the effective $T$ is larger than the geometric average of point values. This implies that Jacob's method can be used for estimating effective $T$ values in many, if not most, formations.
\end{abstract}

\section{Introduction}

\subsection{Basic Concepts and Previous Work}

Formation transmissivity is the most important parameter to be determined in many hydrogeological problems. Transmissivity is often determined in the field using pumping tests. Hydrogeologists have to rely on an interpretation model for the evaluation of pumping test data. Constant rate pumping tests are most often interpreted using the Theis [1935] method or Jacob's semilogarithmic approximation [Cooper and Jacob, 1946]. Both of these techniques use the temporal evolution of pumping-induced drawdown to obtain estimates of transmissivity and storativity under the assumptions of homogeneity, a two-dimensional domain, and confined conditions. Because of the importance of Jacob's method for this work, we review it briefly here (further details can be found in most hydrogeology text books; see, e.g., Freeze and Cherry [1979]). Jacob's method is based on the fact that the Theis well function plots as a straight line on semilogarithmic paper at large dimensionless times. Hence the method consists of drawing a straight line through the late time data points and extending it backward to the point of zero drawdown (time axis intercept), which is designated $t_{0}$. The drawdown per $\log$ cycle is obtained from the slope $m$ of the line. Values for transmissivity $T$ and storativity $S$ can then be found from

$$
\begin{gathered}
T=\frac{2.3 Q}{4 \pi m} \\
S=\frac{2.25 T t_{0}}{r^{2}}
\end{gathered}
$$

Copyright 1998 by the American Geophysical Union.

Paper number 98WR00008.

0043-1397/98/98WR-00008\$09.00 where $Q$ is the constant pumping rate and $r$ is the radial distance to the observation well; if drawdowns are measured at the pumping well, $r$ is equal to the effective radius of the well. The method is considered a valid approximation of the Theis solution if the slope can be derived from data points with $u=$ $r^{2} S /(4 T t)$ smaller than 0.03 for which the approximation error is $<1 \%$.

The analytical solution underlying the Theis and Jacob techniques is based on the assumption of aquifer homogeneity. Other analytical solutions assume that the aquifer can be subdivided into, at most, two or three regions with uniform parameters [e.g., Streltsova, 1988; Butler, 1988, 1990; Butler and Liu, 1991, 1993]. Although such configurations are simplifications of the complex structure of real heterogeneous formations, they can provide insight into the behavior of drawdown in heterogeneous formations. For example, Butler [1990] explains how the Theis and Jacob methods lead to different $T$ values in heterogeneous aquifers because they apply different weightings to different portions of the drawdown curve. As shown in (1), pumping test analysis using Jacob's method is based on the rate of drawdown change. When $T$ only depends on radial distance (axial symmetry), such change reflects aquifer properties only within a ring of influence through which the front of the pressure depression passes within the considered time interval. Therefore estimated transmissivity is independent of the aquifer properties between the inner radius of the ring of influence and the pumping well. However, storage estimates depend on the variations in $T$ between the pumping well and the front of the cone of depression [Butler, 1988]. Butler and Liu [1993] conceptualized the nonuniform aquifer as a uniform matrix into which a disk of anomalous properties has been placed. They found, among other things, that Jacob's method can be used in any laterally nonuniform system to estimate matrix transmissivity if the flow to the pumping well is 
approximately radial during the period of analysis. Oliver [1990] used a perturbation approach to determine the weighting function according to which formation permeabilities are averaged in the determination of apparent values from Jacob's method for pumping test analysis. He found that the averaging area is an annular region of the formation and that both the averaging area and the radius of investigation of a pumping test increase with time. Oliver [1993] used a perturbation approach to study the effect of two-dimensional spatial variations in transmissivity and storativity. He concluded that the area of investigation of a pumping test is bounded by an ellipse that encloses the pumping well and the observation well and that observation well drawdown is relatively sensitive to near-well transmissivity, whereas the observation well drawdown derivative is influenced by the near-well properties for a finite period only.

Previous numerical investigations of transient radial flow in heterogeneous systems resembling real formations by Warren and Price [1961], Lachassagne et al. [1989], and Butter [1991] have been concerned with estimates of transmissivity from pumping tests and their relationship to statistical parameters of the heterogeneous transmissivity field. These authors conclude that transmissivity values obtained from late time data using standard analysis techniques and especially Jacob's method are close to the geometric mean of the transmissivity fields and are a reasonable representation of transmissivity on the regional scale (assuming boundary effects are negligible).

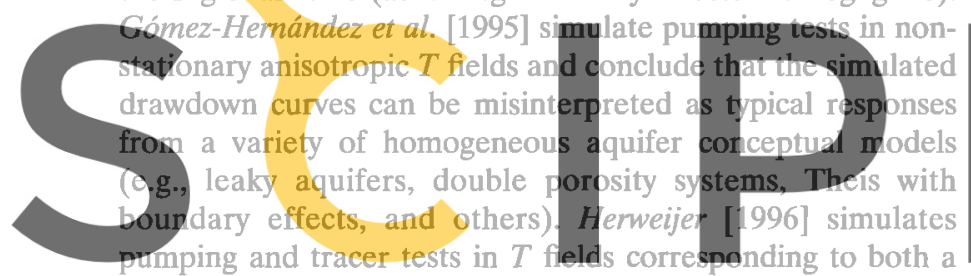
deterministic sedimentological facies model and a Gaussian


which dominate solute transport.

\subsection{Working Hypothesis and Scope of the Work}

We have frequently observed that when applying Jacob's method to late time drawdown data at several observation wells, transmissivity estimates $T_{\text {est }}$ tend to be fairly constant, while the storativity estimates $S_{\text {est }}$ display a great spatial variability. Similar observations have previously been reported by Schad and Teutsch [1994] and Herweijer and Young [1991] in studies in which the Theis method is used to analyze drawdown data from observation wells in heterogeneous alluvial aquifers.

This behavior is surprising in most cases because independent information (such as short term hydraulic tests, geological information, etc.) often suggests that the actual formation transmissivity $T$ is strongly heterogeneous. Conversely, the actual aquifer storativity $S$ is not thought to be highly variable. The variability of the storativity estimates is sometimes attributed to radial flow in homogeneous anisotropic formations [e.g., Streltsova, 1988]. However, methods accounting for homogeneous anisotropic transmissivity [e.g., Neuman et al., 1984; Hantush, 1966; Papadopulos, 1965] did not provide consistent results when applied to our field cases. Storativity depends on porosity and the rock and water compressibility. The latter are believed to be fairly constant at the local scale. Porosity usually varies within a small range compared with hydraulic conductivity, as reported by Guimerà and Carrera
[1997] for fractured rocks, Ptak and Teutsch [1994] for a porous aquifer, Bachu and Underschulz [1992] for sandstone cores, and Neuzil [1994] for clays and shales. Because of this, we have assumed storativity to be homogeneous for our numerical work.

The above paragraphs appear paradoxical: Long-term hydraulic tests lead to small variability of $T_{\text {est }}$ and large variability of $S_{\text {est }}$, while the opposite should be expected for point values of $T$ and $S$. We conjecture that this paradox can be attributed to the fact that methods developed for homogeneous media are being used for interpretation of tests performed in heterogeneous formations.

Our work is centered around the above conjecture. Hence we first provide some field observations to show that this situation indeed exists. Second, we use a series of numerical simulations to show that Jacob's method yields nearly constant $T_{\text {est }}$ and spatially variable $S_{\text {est }}$ in aquifers with variable $T$ and constant $S$. Third, we investigate how the spatial correlation structure of $T$ and the variance of the input $\log T$ field affect the results. Finally, we compare the value of transmissivity obtained using Jacob's method with the effective transmissivity derived for parallel flow.

\section{Field Observations}

We have obtained similar $T_{\text {est }}$ and strongly varying $S_{\text {est }}$ values when using Jacob's method at several field studies in very different types of heterogeneous media, including a single-
shear zone in granitic rock, a fractured gneiss formation, and
alluvial aquifers. In what follows, we first present field data
from the migration experiment of the joint project of Nagra
(Swiss National Cooperative for the Disposal of Radioactive
Waste) and PNC (Power Reactor and Nuclear Fue/Develop-
ment Corporation, Japan) at the Grinsel underground rock laboratory, located in the Swiss Aar Massif within granitic

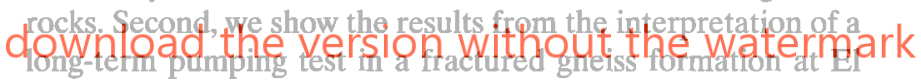
Cabril, which is the site for storage of low- and intermediatelevel radioactive waste in southern Spain. Third, we present two other cases from the literature in which different authors have reported a similar behavior of $T_{\text {est }}$ and $S_{\text {est }}$ values in alluvial aquifers.

\subsection{Migration Experiment at the Grimsel Test Site}

The Grimsel rock laboratory consists of galleries lying $450 \mathrm{~m}$ below the surface within granitic rock. A migration experiment [Frick et al., 1992] was conducted within an almost vertical shear zone that dips parallel to the foliation of the host rock. This shear zone, henceforth designated as the migration shear zone, is more or less isolated from other shear zones and consists of a series of subparallel fractures. Mylonite, cataclastite, and other gouge materials are observed within the subfractures, influencing the permeability within the shear zone. The migration shear zone can be conceptualized as a vertical zone of intersecting fractures with a thickness of $\sim 0.5 \mathrm{~m}$ and can be considered to be a two-dimensional feature at the scale of the tests described here. Hydrological exploration involved drilling eight boreholes into the shear zone. Locations of the boreholes and the laboratory gallery within the shear zone plane are shown in Figure 1. The intervals in the boreholes were isolated with packers for the performance of hydraulic and tracer tests.

Single-hole short-term pumping tests of 5-10 s in duration 
(rates between 10 and $200 \mathrm{~mL} / \mathrm{min}$ ) were conducted to obtain point estimates for the transmissivity. These tests were analyzed with the MARIAJ code [Carbonell and Carrera, 1992], which uses an automatic optimization procedure coupled with the general analytical solution of Barker [1988]. Transmissivity estimates range between $10^{-8}$ and $5 \times 10^{-6} \mathrm{~m}^{2} / \mathrm{s}$, indicating strong local heterogeneity, while storativity estimates vary from $5 \times 10^{-10}$ to $10^{-5} \mathrm{~m}^{2} / \mathrm{s}$ [Meier, 1997]. The large variation in the $S$ estimates is believed to reflect the uncertainties in estimating $S$ from single-well tests but may also be a product of an analysis method based on an analytical solution for homogeneous aquifers. Cross-hole constant-rate pumping tests of $\sim 2$ hours in duration were performed in boreholes $4,6,8,9$, and 10 using pumping rates of $200 \mathrm{~mL} / \mathrm{min}$. Analysis of the late time data at both the pumping and the observation wells with Jacob's method resulted in a virtually constant $T_{\text {est }}$ value of $\sim 10^{-6}$ $\mathrm{m}^{2} / \mathrm{s}$ for all tests and in a broad range of $S_{\text {est }}$ values extending from $4 \times 10^{-7}$ to $5 \times 10^{-2} \mathrm{~m}^{2} / \mathrm{s}$ [Meier, 1997]. Transmissivities and storativities are displayed in Figures $2 \mathrm{a}$ and $2 \mathrm{~b}$ for the single-hole tests and for the cross-hole test performed by pumping in borehole 9. A semilog plot of the drawdown curves for the cross-hole pumping test in borehole 9 is shown in Figure 3 as an example of the drawdown behavior seen in all the cross-hole tests. Straight lines with similar slopes start developing after about $3500 \mathrm{~s}$ for all drawdown curves. Boundary effects due to the influence of the gallery are not observed during these tests. Note that inverse geostatistical modeling of the steady state hydraulic head field and the transient drawdow data reveals a variation in transmissivity of several orders of magnitude and the existence of highly transmissive channels within the shear zone [Meier et al, 1997]. Such channels may be rosponsible for the relatively large drawdown at borchole 5 shown in Figure 3

2.2. El Cabril

Register El Eabril site is located in a very spatsely populated area are composed of biotitic gneiss and metaarkoses. These formations were affected by the compressive Hercynian deformation, so the formations follow a predominantly WNW-ESE and NW-SE trend and are characterized by primarily vertical dips. Several sets of transverse fractures (directions $60^{\circ} \mathrm{N}, 90^{\circ} \mathrm{N}$, and

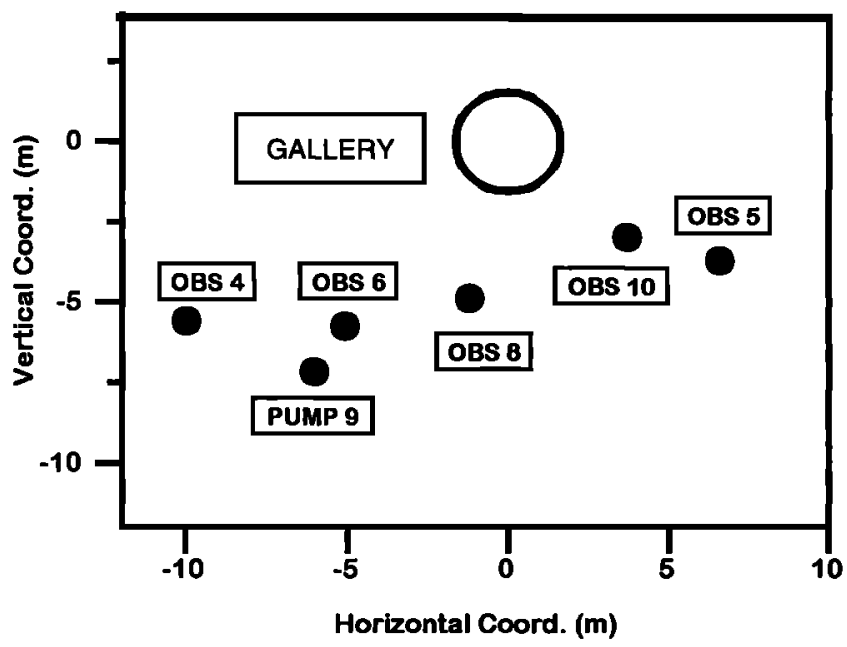

Figure 1. Locations of the boreholes and the laboratory gallery in the migration shear zone at the Grimsel test site.
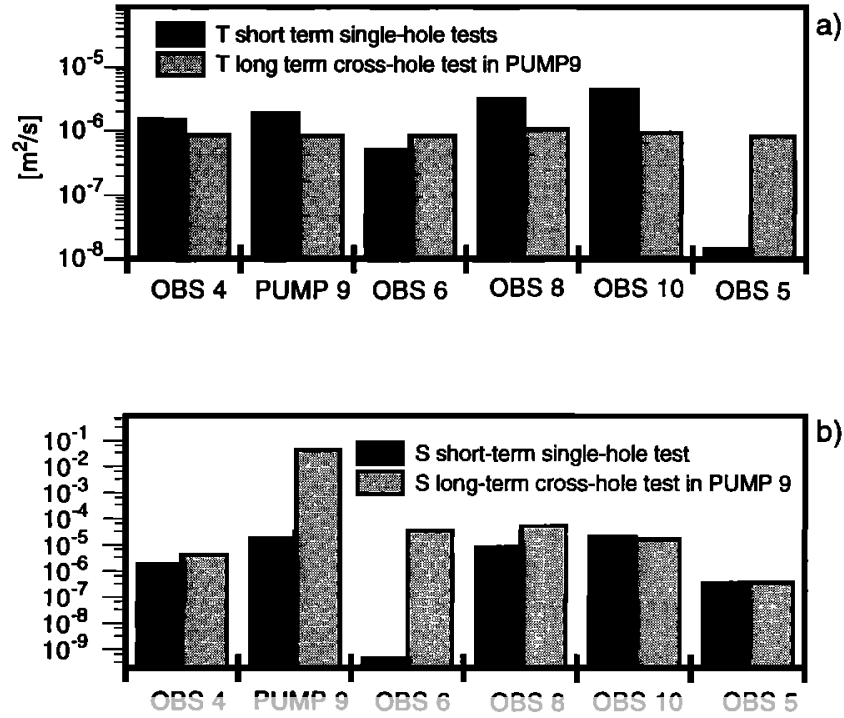

Figure 2. Results from single-hole and cross-hole tests conducted in the migration shear zone for (a) transmissivity estimates and (b) storativity estimates. Note that transmissivities derived from short-term single-hole tests display a large variability in contrast to transmissivities from cross-hole tests, which remain virtually constant. Storativity estimates span a wide range of values for single-hole and cross-hole tests.

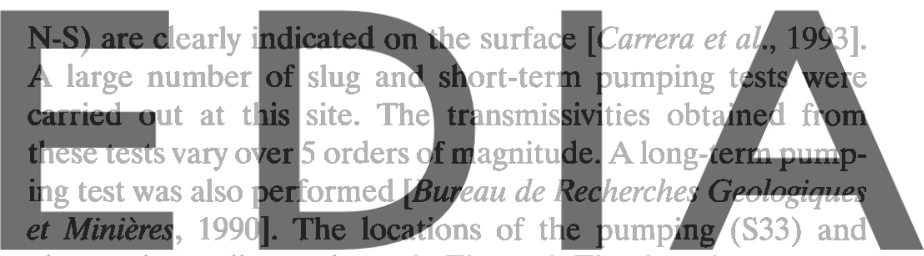

observation wells are shown in Figure 4. The drawdown curves from individual observation wells were interpreted separately disingntead the versicanowithautane, wateribark the assumption of a homogeneous and isotropic medium. The estimated parameters obtained for each well are shown in Figure 5. The $T_{\text {est }}$ values range from 0.38 to $0.52 \mathrm{~m}^{2} / \mathrm{d}$, while the $S_{\text {est }}$ values range from $10^{-4}$ to $3 \times 10^{-2} \mathrm{~m}^{2} / \mathrm{d}$. Thus the $T_{\text {est }}$ values are almost constant, while the $S_{\text {est }}$ values range over



Figure 3. Semilog plot of the drawdown observed at the pumping well and the observation points during a cross-hole test in the migration shear zone. 


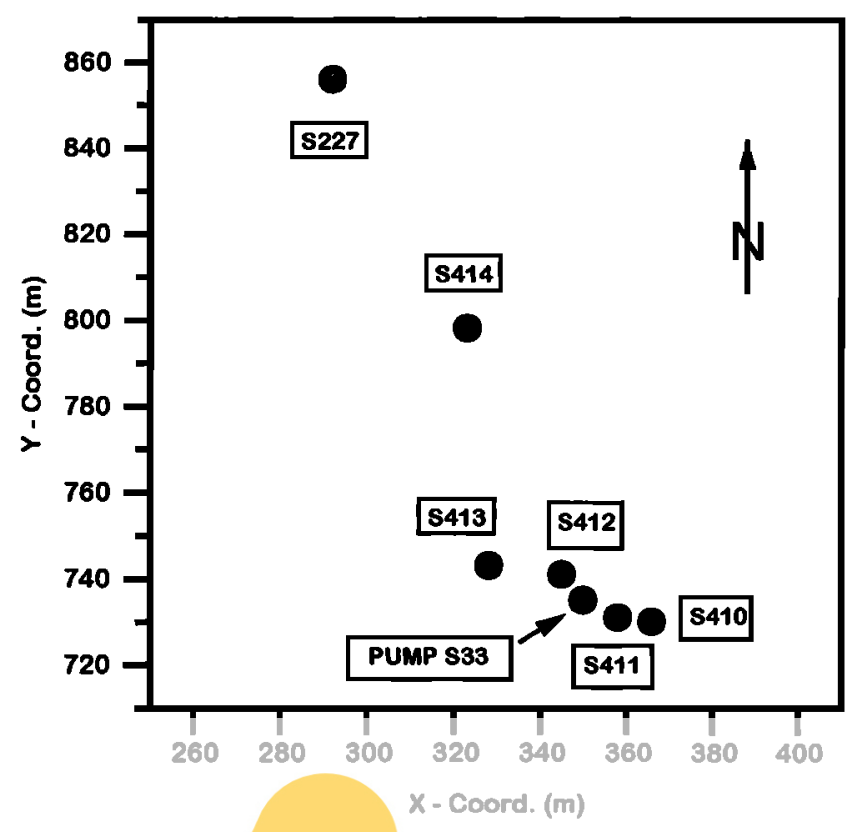

Figure 4. Location of pumping and observation wells at the El Cabril site.

more than 2 orders of magnitude. This test was later interpreted by means of a finite element model automatically calibrated with the approach of Carrera and Neuman [1986]. Drawdowns could only be closely matched by assuning that $\mathbf{S 2 2 7}$ (the observation well at which the smallest $S_{\text {est }}$ was obtained) was connected to S33 through a fracture, a likely situation given the geology at the site. Note that a convergent flow tracer test was performed at this site by iajecting a different while well S33 was pumped. Porosities were estimated under

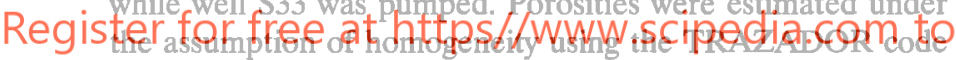
[Benet and Carrera, 1992]. The pattern of estimated porosities is very similar to that of $S_{\text {est }}$ in Figure 5 [Sanchez-Vila et al.g 1992; Carrera, 1993]. This suggests that relatively high transmissivity pathways are reflected not only in $S_{\text {est }}$ but also in estimated porosity when homogeneous media solutions are used.

\subsection{Field Observations Reported in the Literature}

Schad and Teutsch [1994] provide an extensive data set from a series of pumping tests performed in a highly heterogeneous aquifer at the Horkheimer Insel field site in the Neckar Valley of Germany. Because of its relevance to our work, we review briefly some parts of their study. The unconfined aquifer in which the tests were performed consists of $\sim 4 \mathrm{~m}$ of poorly sorted sand and gravel deposits of a braided river origin. This aquifer is overlain by 5-6 $\mathrm{m}$ of mostly clayey flood plain deposits and underlain by a hydraulically tight clay. Hydraulic conductivity data derived from grain-size distributions had an overall variance of $\log$ conductivity equal to 2.35 , indicating significant heterogeneity. Schad and Teutsch performed 26 pumping tests (duration of 2 hours) at different wells at the site. During each of these tests, up to four observation wells were monitored at radial distances of 2 to $36 \mathrm{~m}$ from the pumping well. The analysis of the early time data, using the Theis method, resulted in a broad range of $T_{\text {est }}$ values $(1.6 \times$ $10^{-2}$ to $3.2 \times 10^{-1} \mathrm{~m}^{2} / \mathrm{s}$ ) and in a very broad range of $S_{\text {est }}$ values $\left(5.8 \times 10^{-4}\right.$ to $\left.1.0 \times 10^{-1} \mathrm{~m}^{2} / \mathrm{s}\right)$. The analysis of the late time data, using the Theis method, resulted in a small range of $T_{\text {est }}$ values $\left(2.4 \times 10^{-2}\right.$ to $\left.5.0 \times 10^{-2} \mathrm{~m}^{2} / \mathrm{s}\right)$ and in a broad range of $S_{\text {est }}$ values $\left(1.7 \times 10^{-2}\right.$ to $\left.1.3 \times 10^{-1} \mathrm{~m}^{2} / \mathrm{s}\right)$. They also conducted a long-term ( 96 hour) pumping test in which drawdown was monitored at 23 observation wells. The analysis of this test with the Theis method resulted in a very small range of $T_{\text {est }}$ values $\left(2.9 \times 10^{-2}\right.$ to $\left.3.5 \times 10^{-2} \mathrm{~m}^{2} / \mathrm{s}\right)$ and in a broad range of $S_{\text {est }}$ values $\left(2.6 \times 10^{-2}\right.$ to $\left.1.1 \times 10^{-1} \mathrm{~m}^{2} / \mathrm{s}\right)$. Schad and Teutsch also mention that $S_{\text {est }}$ values show a large variability at short observation distances and a progressively smaller variability for larger distances. They point out that the variations in $S_{\text {est }}$ should be a function of the relative transmissivity of the flow path between the pumping and the observation well. If this path has a high relative transmissivity, $S_{\text {est }}$ should be small and vice versa.

Herweijer and Young [1991] present a qualitative model of aquifer heterogeneity for the interpretation of spatial and temporal variability of hydraulic parameters derived from pumping tests in a heterogeneous fluvial aquifer at Columbus Air Force Base, Mississippi. Their results from pumping tests analyzed with the Theis method cover a wide range for storativity estimates and a relatively small range for transmissivity estimates. They conclude that the storage estimates show a strong dependence on the flow pattern induced by pumping and the degree of interconnection of high hydraulic conductivity lenses between the pumping and observation wells.



lowing steps: (1) generation of two-dimensional (2-D) heterogeneous $T$ fields, (2) simulation of transient radial flow toward

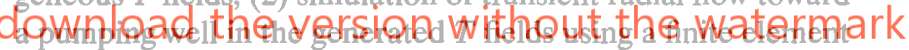
code, (3) analysis of the drawdown curves simulated at all nodes of the grid using Jacob's method, (4) generation of maps showing the spatial distribution of the $T_{\text {est }}$ and $S_{\text {est }}$ values and drawdown, and (5) analysis of the results. Regarding the analysis of the results, we first compare the spatial $S_{\text {est }}$ distribution with the spatial structure of the input $T$ fields. Second, we check whether the average of the $T_{\text {est }}$ values (designated as $T_{\text {avg }}$ ) is somewhat representative of the full domain by comparing it with the effective transmissivity obtained from theoretical considerations and from numerical analysis of parallel flow in the same $T$ fields.

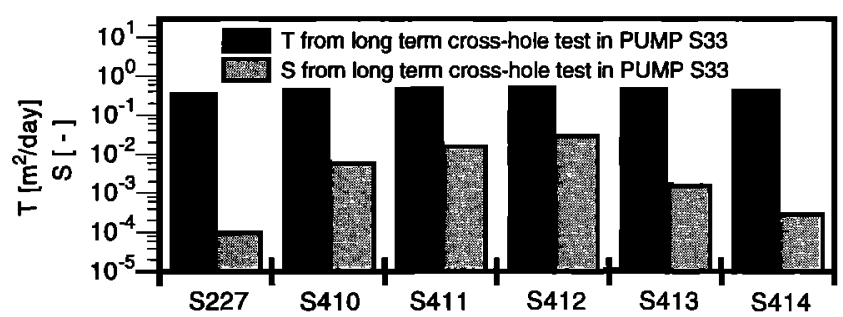

Figure 5. Transmissivity and storativity estimates obtained from the interpretation of drawdown curves at each observation well for the long-term pumping test in borehole S33 at the El Cabril site. Again, $T$ estimates remain virtually constant, while $S$ estimates span 3 orders of magnitude. 
$\mathrm{h}=0$

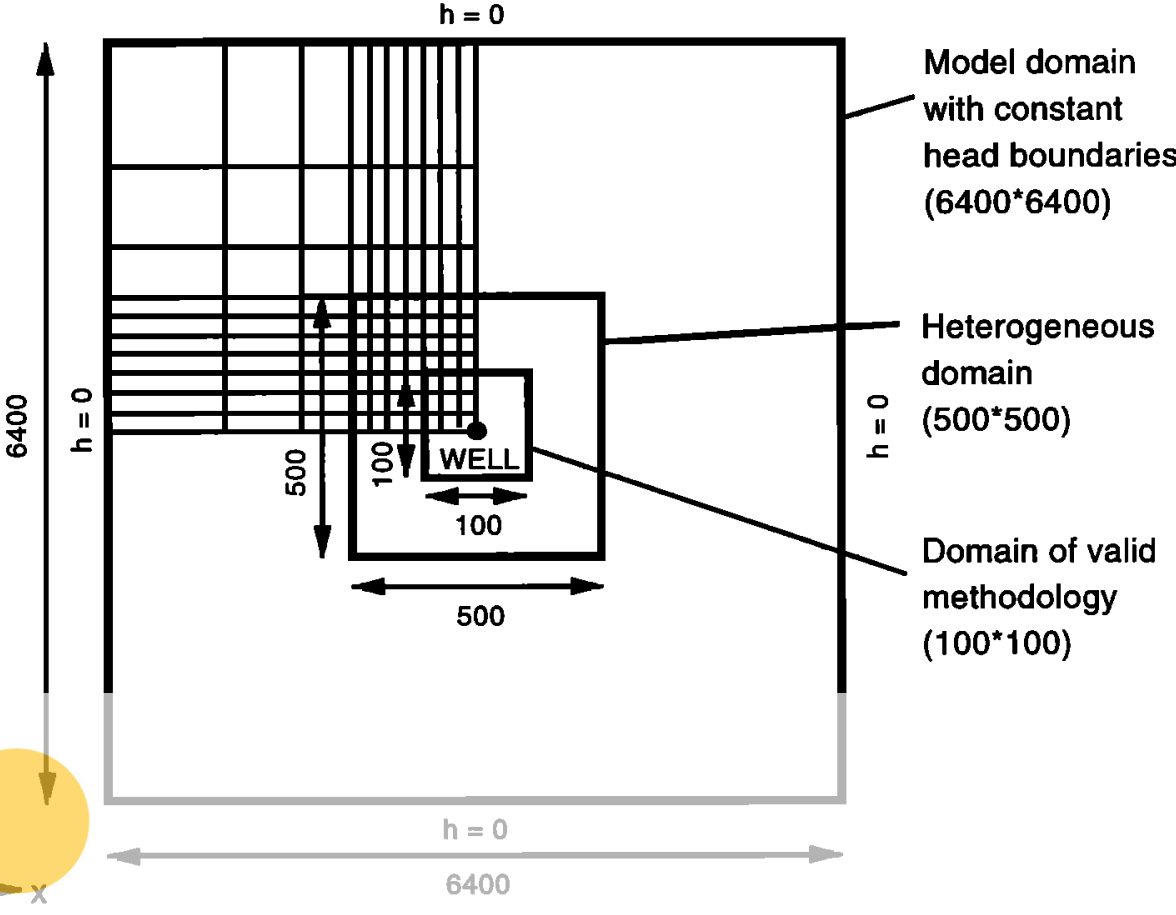

Figure 6. Schematic drawing of the model setup indicating the discretization scheme in the top left quadrant, the pumping well location, the full model domain, the heterogeneous domain, and the heterogeneous subdomain for which our methodology is considered valid. values.

To minimize boundary effects, the heterogeneous domain of $500 \times 500$ square elements of unit area is bounded on all sides by 20 rectangular elements of increasing size as shown schematically in Figure 6. The $T$ values of these elements are set equal to the geometric mean transmissivity of the random $T$ field $(T g=1.0)$. Constant head conditions are applied to the external boundaries of the full domain. This full domain is square in shape and consists of 291,600 elements. A homogeneous input storativity of $\mathbf{1 . 0}$ is used for all the simulations. Although 1.0 is a physically implausible value for storativity, this assignment has no effect on the results $(S=1.0$ was chosen so that the average diffusivity $(T / S)$ of the heterogeneous domain was 1.0). The pumping well is located at the center of the domain. The transient flow equation is solved with the finite element computer code FAITH [Sánchez-Vila et al., 1992], which is especially designed to work with a large number of elements. Drawdown values are calculated every 10 time units and are written to a file every 100 time units for all nodes of the finite element mesh. The $T_{\text {est }}$ and $S_{\text {est }}$ values are calculated with Jacob's method for all nodes by fitting a straight line through the last three drawdown points. Special care is taken to make sure that drawdown curves are not sensitive to the homogeneous outer zone surrounding the het-

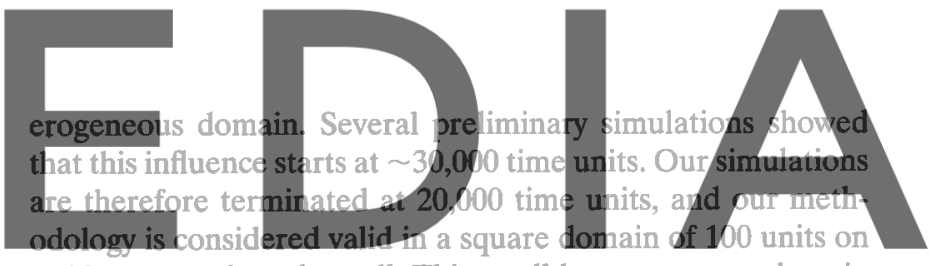

a side centered on the well. This small heterogeneous domain


method over the same time range for all observation points. This results in Jacob's method being applied at different dimensionless times $\left(1 / u=4 T t /\left(r^{2} S\right)\right)$ at different points in the domain. Since the appropriateness of the approximation underlying Jacob's method is a function of the dimensionless time, the appropriateness of this approximation varies as a function of location within the domain. For example, the dimensionless time is $\mathbf{1 5 . 7 9}$ for a radius of 71 units, corresponding to the distance between the pumping well and the corners of the domain of valid methodology, for $t=19,900$, which is the average time of the small time period from 19,800 to 20,000 time units for which Jacob's method is applied, for an average $T=1.0$ and for $S=1.0$. For $1 / u=15.79$ the error in using Jacob's method instead of the Theis method is about 3.0\%, assuming that these criteria are valid for heterogeneous conditions. The errors are considerably smaller at the center of the domain (about $0.2 \%$ for a radius of 30 units and the same parameters used above). Therefore we expect to obtain a slight radial trend with smaller $T$ values in the center and larger $T$ values at further distances from the pumping well as a consequence of applying Jacob's method over the same time range for all observation points. However, we want to stress that the above considerations are strictly valid only for homogeneous conditions and may not be appropriate for highly heterogeneous $T$ fields.

The arithmetic mean of the $10,000 T_{\text {est }}$ values within the 


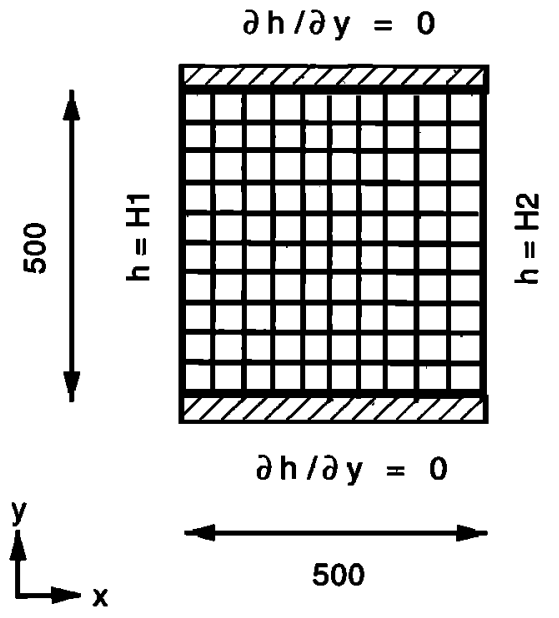

Figure 7. Boundary conditions used to compute effective transmissivity for parallel flow conditions in a heterogeneous $T$ field.

small domain, which are obtained using Jacob's method, will
be designated as $T_{\text {avg }}$ throughout the remainder of this work.
$T_{\text {avg is compared (1) with the geometric sample mean }\left(T_{g}\right) \text { of }}$
the input $T$ fields and (2) with the effective transmissivity
obtained from parallel flow simulations ( $T_{\text {effp }}$ ) using the same
$T$ fields as in the radial flow simulations. The motivation for
this twofold comparison is basect on the work of Sunchez-Vila
et at. [1996]. This work suggests that the assumption of multi-
lognormality may not be valid in many real field cases, even if
point $T$ values display a lognormal distribution and, further-
more, that the appearance of scale effects in $T$ may be attrib-
"ted to departures from multilognormality. Here the term
"scale effect" is used to describe the apparent increase of $T$ with the size of the definition domain and, more specifically, Register increase of large scale effective $T$ with respet to the geoulations with a mean parallel gradient in nonmultilognormal $T$ fields and showed that the effective transmissivity $T_{\text {eff }}$ does not necessarily agree with $T_{g}$, contrary to $T_{\text {eff }}$ derived for multilognormal distributions. Following their approach, we obtain $T_{\text {effp }}$ for $T$ fields by solving the steady state flow equation under very simple boundary conditions as shown in Figure 7. When applied to our heterogeneous $T$ fields (large domain of $500 \times 500$ cells), we obtain a mean gradient that is constant and parallel to the $x$ coordinate axis. Under such conditions, the effective transmissivity in the $x$ direction is given by $T_{\text {effpx }}=Q_{T} \times L / \Delta H$, where $Q_{T}$ is the total flux per unit width into (and out of) the domain and $L$ is its length. A change of boundary conditions is used to find the effective transmissivity in the $y$ direction $T_{\text {effpy }}$. The geometric mean $T_{\text {effp }}=$ $\sqrt{T_{\text {effpx }} T_{\text {effpy }}}$ is considered an appropriate quantity for the comparison with our simulation results ( $\left.T_{\text {avg }}\right)$. The $T_{g}, T_{\text {effp' }}$ and $T_{\text {avg }}$ values for all our test cases are given in Table 1 .

It should be stressed that a single effective transmissivity, defined as the tensor that relates the expected values of flow and head gradient, can only be defined for parallel flow conditions, for which it is equal to $T_{g}$ under relatively broad conditions [Matheron, 1967]. De Marsily [1986, p. 82] states, "If the flow is not uniform (converging radial, for example), there is no law of composition, constant in time, that makes it possible to define a mean darcian permeability. This problem is quite worrying from the conceptual viewpoint in so far as it is precisely through pumping tests in wells that the transmissivity of an aquifer is measured in situ." It should be stressed that the problem of an effective transmissivity for radial flow conditions is not examined here, because we are primarily interested in the relationship between the transmissivity estimates provided by an interpretation model for pumping test analysis (in our case Jacob's method) and the effective transmissivity for parallel flow conditions ( $\left.T_{\text {effp }}\right)$, which is a representative parameter for most problems in hydrogeology.

In section 4 we examine the relation between $T_{\text {effp }}$ and $T_{\text {avg }}$ for three conceptual models for aquifer heterogeneity: (1) a multilognormal $T$ field, (2) a nonmultilognormal $T$ field with connected high $T$ zones without a large-scale trend, and (3) a fractal field with a large-scale trend.

\section{Test Cases}

\subsection{Test Case 1: Multilognormal Random Field,} Effect of $\log T$ Variance $\sigma_{Y}^{2}$

The objective of the first test case is to corroborate the field observations and to investigate the influence of $\sigma_{Y}^{2}$ on $T_{\text {est }}$ and $S_{\text {est. }}$. We simulate three $T$ fields, assuming $Y=\ln T$ is a stationary multinormal random function characterized by the mean $\langle Y\rangle\left(\approx 0.0\right.$ for the three $T$ fields), the variances $\left(\sigma_{Y}^{2}=\right.$ $0.25,1.0$, and 4.0 ), and the variogram (a spherical isotropic model with a range of 26 unit lengths, which corresponds to an integral scale of $\sim 10$ unit lengths). The $T$ fields are generated by conditioning on the four square elements surrounding the
rode located at he center, which serves as the pumping well,
fixing their values to $T_{g}=1.0, T_{g}$ being the geometric nean
of the point $T$ values. The effect of varying the transmissivity at
the well $\left(T_{w}\right)$ will be investigated in test case 3 . The $I$ field
vith $\sigma_{Y}^{2}=1.0$ is shown in Figure $8 \mathrm{a}$, where the black areas
represent the must transmissive quartile and the white areas represent the least transmissive one. Table 1 indicates that

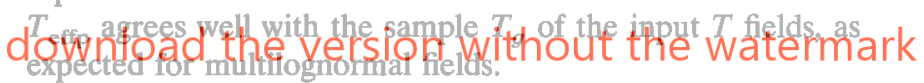

Figures $8 \mathrm{c}$ and $8 \mathrm{~d}$ show the simulated drawdown curves at several observation points located in different directions ( 1 to 8 ) but at the same distance $R$ from the pumping well (see

Table 1. Comparison Between Effective Transmissivity for Parallel Flow Conditions and Average Transmissivity Estimates Obtained From Jacob's Method for Different Integral Scales, Pumping Well Transmissivity, $\log T$ Variances, and Geometric Mean Transmissivity

\begin{tabular}{ccccccc}
\hline $\begin{array}{c}\text { Test } \\
\text { Case }\end{array}$ & $T_{w}$ & $I$ & $\sigma_{Y}^{2}$ & $T_{g}$ & $T_{\text {eff }} / T_{g}$ & $\begin{array}{c}T_{\text {avg }} / T_{g}, \\
\pm \text { Range }\end{array}$ \\
\hline 1 & 1.00 & 10 & 0.25 & 1.00 & 1.00 & $1.01 \pm 2.1 \mathrm{E}-4$ \\
1 & 1.00 & 10 & 1.01 & 1.03 & 1.00 & $0.97 \pm 2.6 \mathrm{E}-4$ \\
1 & 1.00 & 10 & 4.04 & 1.00 & 0.99 & $0.96 \pm 8.5 \mathrm{E}-4$ \\
3 & 1.65 & 10 & 1.01 & 1.03 & 1.00 & $0.97 \pm 2.5 \mathrm{E}-4$ \\
3 & $\mathbf{0 . 6 1}$ & 10 & 1.01 & 1.03 & 1.00 & $0.97 \pm 2.7 \mathrm{E}-4$ \\
4 & 1.00 & 25 & 1.03 & 1.00 & 1.10 & $1.13 \pm 4.2 \mathrm{E}-4$ \\
4 & 1.00 & 25 & 2.06 & 1.02 & 1.24 & $1.23 \pm 6.3 \mathrm{E}-4$ \\
4 & 1.00 & 25 & 4.12 & 1.00 & 1.58 & $1.48 \pm 7.6 \mathrm{E}-4$ \\
5 & 1.00 & $\cdots$ & 0.74 & 0.97 & 0.97 & $1.07 \pm 1.2 \mathrm{E}-3$ \\
\hline
\end{tabular}

$T_{w}$, pumping well transmissivity; $I$, integral scale; $\sigma_{Y}^{2}, \log T$ variance; $T_{g}$, geometric mean transmissivity; $T_{\text {effp }}$, effective transmissivity for parallel flow conditions; $T_{\text {avg, }}$, average transmissivity estimate. Notice that $T_{\text {effp }}$ and $T_{\text {avg }}$ are very close except when $T$ is nonstationary (test case 5). Notice also the small range of $T_{\text {avg }}$ Read $1.01 \pm 2.1 \mathrm{E}-4$ as $1.01 \pm 2.1 \times 10^{-4}$. 

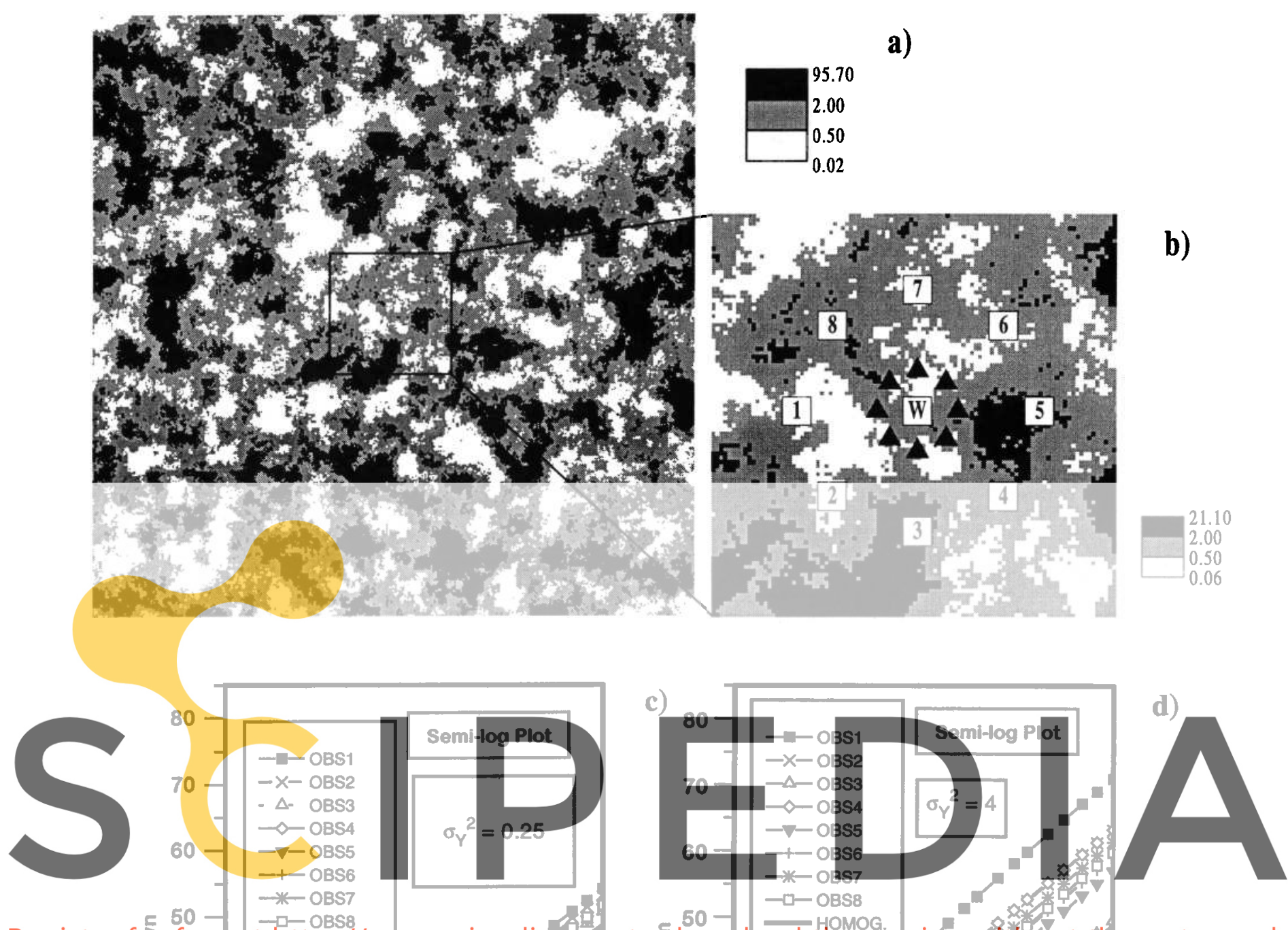

Register fogr free at httpsildavww.scipedia.com to


Figure 8. Test case 1. (a) Multilognormal random $T$ field of $500 \times 500$ units with $\sigma_{Y}^{2}=1.0$ and (b) subdomain of $100 \times 100$ units for which the methodology is considered valid are shown here. "W" indicates the well location. The numbers indicate the observation points at a radial distance $R=30$ units. The solid triangles indicate the observation points at $R=10$ units. (c) and (d) Semilog plots of the simulated drawdown at the observation points shown in Figure $8 \mathrm{~b}$ for $\sigma_{Y}^{2}=0.25$ and 4.0 are shown. Note that late time slopes are approximately equal for all curves.

Figure 8b), for the $T$ fields with $\sigma_{Y}^{2}=0.25$ and 4.0. Results are presented for $R=10$ and $R=30$. The corresponding drawdown curves for a homogeneous $T$ field with $T=T_{g}=1.0$ and $S=1.0$ are shown for comparison. Note that only a small number of drawdown points are shown on each curve to keep the figures clear. All drawdown curves exhibit late time slopes which are similar to that corresponding to the homogeneous case. In Figure $8 d$ the drawdown curves at observation points 
2 and 5 at radial distances of 30 unit lengths from the well illustrate the variability in early time pressure response in heterogeneous media. Observation point 2 and the well are connected through a zone of low $T$, which can easily be recognized in Figure $8 \mathrm{~b}$. The drawdown response is therefore delayed with respect to the homogeneous case. Jacob's method yields a $S_{\text {est }}$ greater than the formation $S$ because $t_{0}$, the intercept with the time axis of the straight line fitted through the last data points, is greater than that of the homogeneous case. On the contrary, observation point 5 and the well are connected through a zone of high $T$. The drawdown response is therefore earlier in time than the homogeneous case, resulting in a $S_{\text {est }}$ smaller than the formation $S$. A high $\sigma_{Y}^{2}$ results in greater differences between the drawdown curves at the same radial distance to the well, which in turn results in a higher variability of $S_{\text {est }}$ and vice versa. The differences between the drawdown curves decrease with increasing radial distance to the well, causing a decrease of the $S_{\text {est }}$ variance with the radial distance from the well, as the flow nrocess samples a larger number of heterogeneities.

This is consistent with the field observations of Schad and Teutsch [1994] discussed in section 2. Note that for $R=10$ the solid line (homogeneous case) is below all responses in Figure $8 \mathrm{c}$ and all but one in Figure 8d for times later than 200 time units at which the pressure front has already passed the observation points at $R=10$. This is due to the increased slopes of the drawdown curves (with respect to the homogeneous case) between 100 and 500 time units. 'The increased slopes reflect

the relatively low geometric average of 0.8 of the point $T$

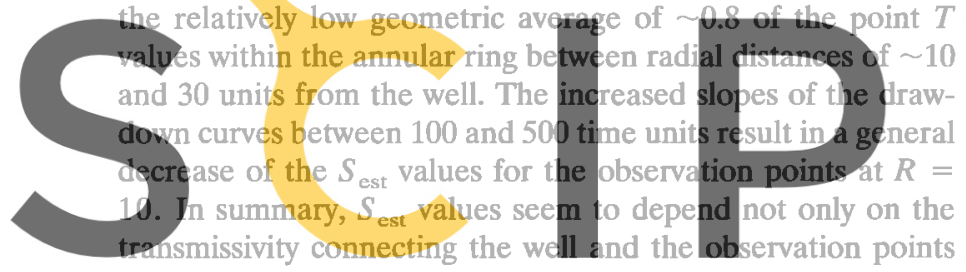

but also on transmissivities within a certain catchment area

Register furfir foth the well and the observation points. for the $T$ fields with $\sigma_{Y}^{2}=0.25$ and 4.0 are shown in Figures 9a-9f. The following can be concluded from these figures: (1) The $T_{\text {est }}$ values obtained from Jacob's method are very close to $T_{g}=1.0$, which is equal to $T_{\text {effp }}$ in multilognormal $T$ fields (as discussed in section 3 , the radial trend of the $T_{\text {est }}$ distributions may be attributed to applying Jacob's method over the same time range to all points, regardless of the distance to the pumping well); (2) the $S_{\text {est }}$ values vary strongly in space despite the fact that the formation $S$ was homogeneous; (3) the spatial structures of $S_{\text {est }}$ resemble each other for different values of $\sigma_{Y}^{2}$ (see Figure 10c for $\sigma_{Y}^{2}=1.0$ ), and the variance of $S_{\text {est }}$ depends on $\sigma_{Y}^{2}$; and (4) a dependence between the heterogeneous input $T$ field (Figure 8b) and the spatial distribution of $S_{\text {est }}$ does exist, although the $S_{\text {est }}$ field is smoother. Note that we have also found that results are independent of the integral scale $(I)$ by performing the same test with different values of $I$.

\subsection{Test Case 2: Multilognormal Random Field, Effect of Support Scale}

The idea behind test case 2 is to examine what happens when we sample the field more coarsely and assign the data as block values. A new multilognormal random field with increased support scale is generated using the $T$ field with $\sigma_{Y}^{2}=1.0$ corresponding to the first test case, while maintaining $\langle Y\rangle$ and changing only slightly $\sigma_{Y}^{2}$ and the variogram. The generation procedure is the following: The $T$ value of one element of the original $T$ field is assigned to its surrounding elements, forming blocks of $3 \times 3$ unit lengths. This procedure is repeated for every third element in the $x$ and $y$ directions for the $T$ field shown in Figure 8a. The central domain of the resulting $T$ field with the increased support scale is shown in Figure 10a. Comparison with Figure $8 \mathrm{~b}$ indicates that the main features of the original $T$ field are maintained. The spatial distributions of $S_{\text {est }}$ obtained for the $T$ field with increased support scale and for the original $T$ field are shown in Figures $10 \mathrm{~b}$ and $10 \mathrm{c}$, respectively. The change of support scale results only in minor changes of the spatial $S_{\text {est }}$ distribution. The increase of support scale has virtually no effect on the spatial distribution of $T_{\text {est }}$, which is therefore not shown.

\subsection{Test Case 3: Multilognormal Random Field, Effect of Transmissivity at the Well}

In the $T$ fields presented in the first two cases the transmissivity at the well $\left(T_{w}\right)$ was selected to be equal to $T_{g}$. In test case 3 we are interested in examining the effects that changing the $T_{w}$ value would have on the $S_{\text {est }}$ and $T_{\text {est }}$ values. For this purpose, two new fields were generated by conditioning the simulations on $T_{w}$ values different from $T_{g}=1.0$. The two new values were $T_{w}=0.61$ and $T_{w}=1.65$. The statistical parameters and the random number seed corresponding to the first test case were maintained. Comparison of the subdomains of the fields generated with $T_{w}=1.0, T_{w}=0.61$, and $T_{w}$ 1.65 (Figures 8b, 11a, and 11b, respectively) indicates that only

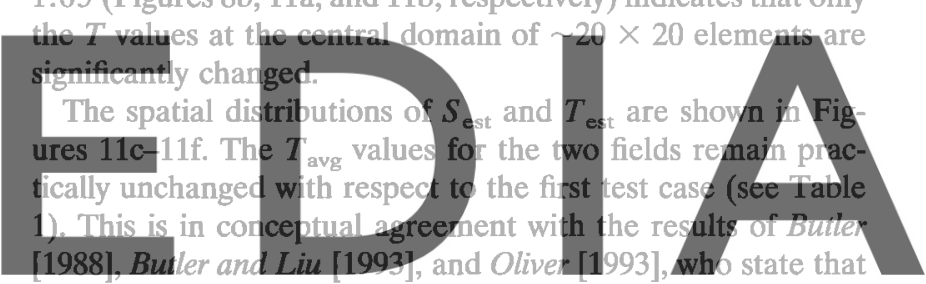

methods of transmissivity estimation that use the late time rate of change of drawdown, instead of the total drawdown, are less the radial trend of the $T$ est distributions, which is similar to the one observed for test case 1 , may be attributed to applying Jacob's method over the same time range to all points, regardless of the distance to the pumping well.

Noticeable differences between the two simulations are restricted to the $S_{\text {est }}$ in the central domain where the input $T$ fields are different. High $T_{w}$ results in high $S_{\text {est }}$ next to the well and vice versa. Note that the results within a radial distance of $\sim 5$ unit lengths around the well are considered to be affected by numerical errors due to a poor spatial discretization in the vicinity of the well. However, our qualitative interpretation of the simulations seems to be in agreement with the common knowledge that $S_{\text {est }}$ obtained from single-hole hydraulic tests can disagree considerably with formation $S$ (a detailed discussion about this topic is given by Butler [1988, 1990]). For the case of $S_{\text {est }}$ that is considerably greater than formation $S$ we expect that the pumping well is situated within a zone of $T>$ $T_{\text {est }}$ or vice versa. The formation $S$ has then to be calculated from rock and fluid properties, which is a common practice in the field of reservoir engineering. Note that differences between $S_{\text {est }}$ and real aquifer $S$ are generally attributed to skin effects [e.g., Earlougher, 1977], which are conceptually equivalent to heterogeneities near the well. The fact that the $S_{\text {est }}$ values at the well are highly sensitive to near-well nonuniformity may potentially be utilized to characterize small-scale heterogeneity using $S_{\text {est }}$ values from single-hole tests at differ- 

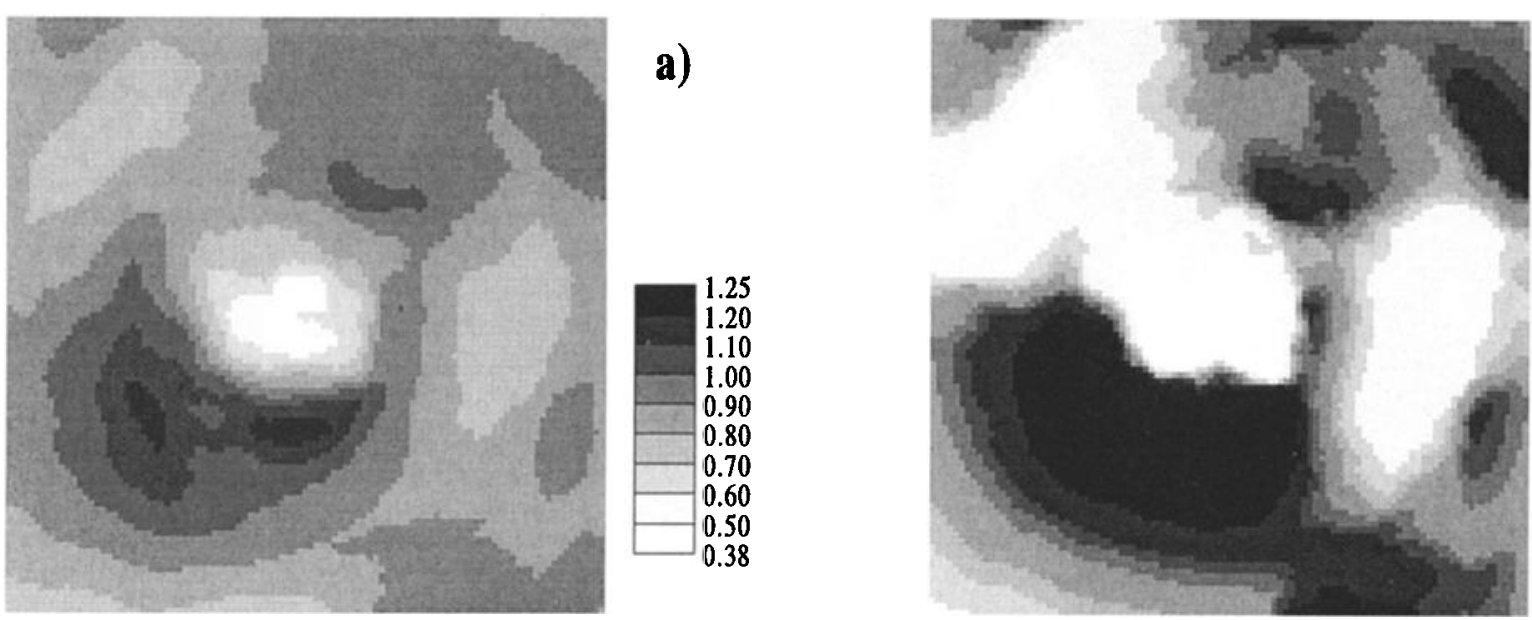

b)
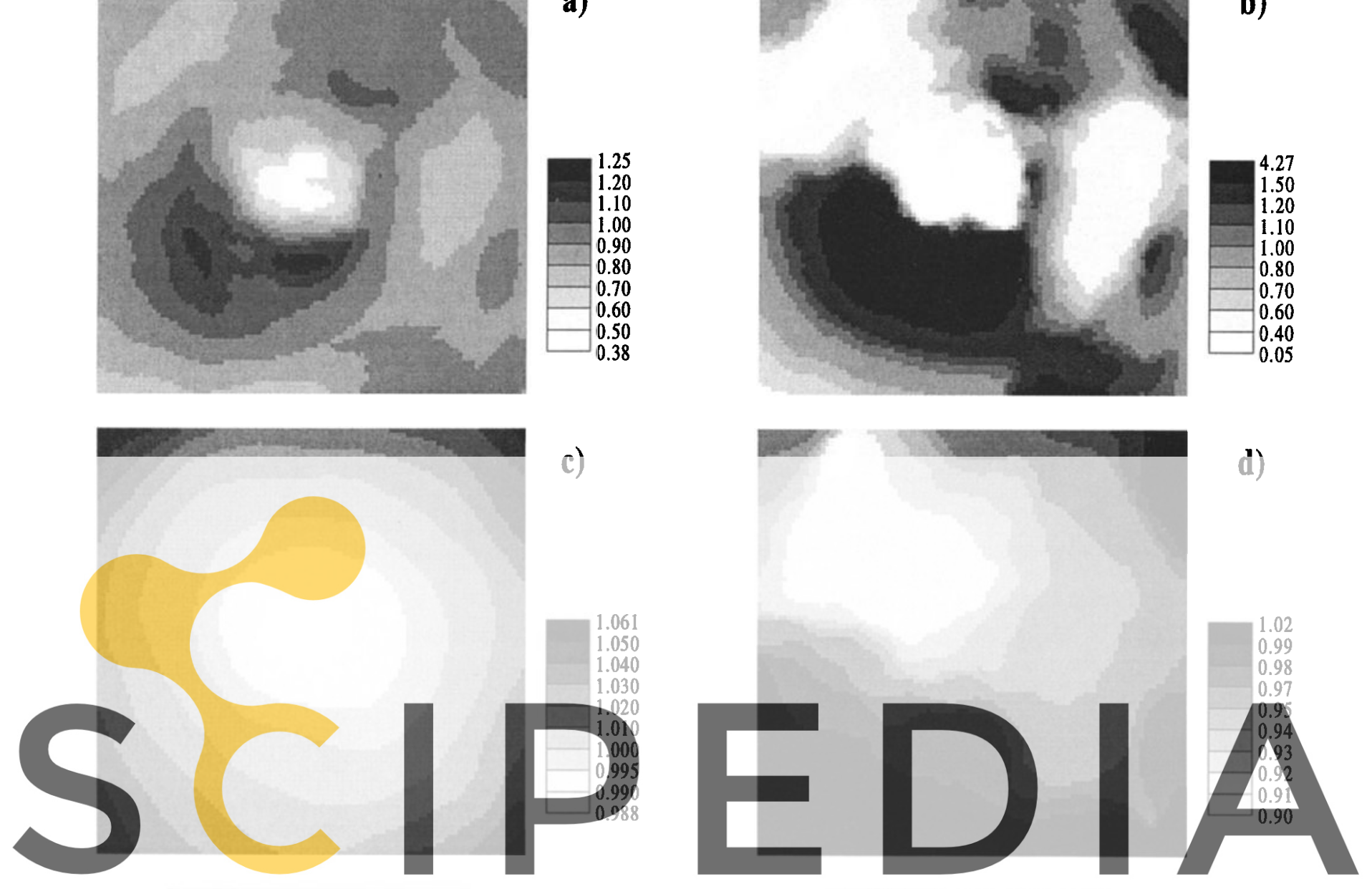

Register for free at https//www.scipedia.com to download the version without the wftermark
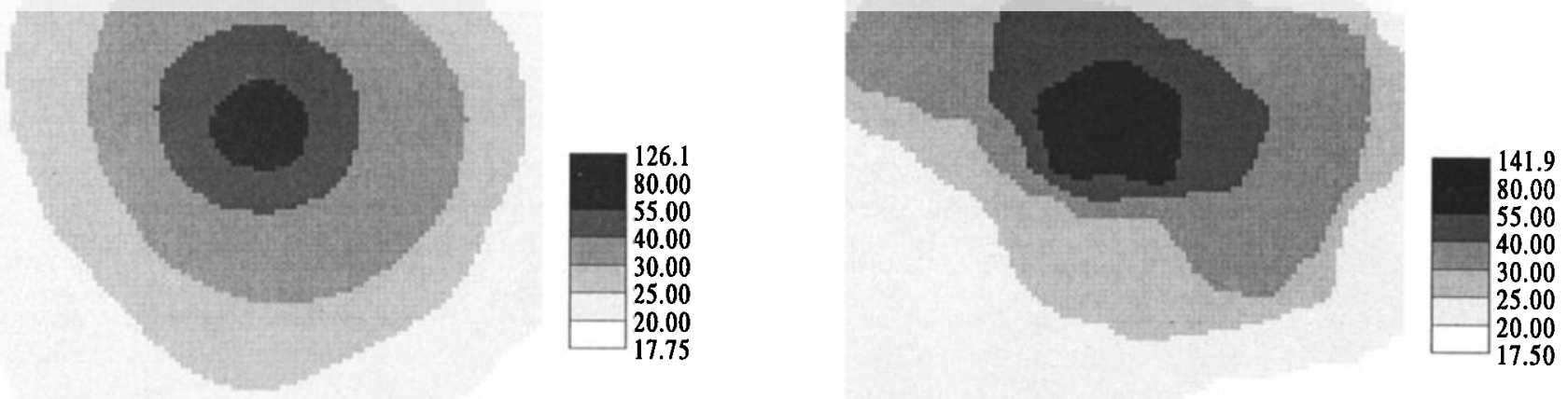

Figure 9. Test case 1: (a) and (b) spatial distribution of $S_{\text {est }}$ for $\sigma_{Y}^{2}=0.25$ and 4.0, (c) and (d) spatial distribution of $T_{\text {est }}$ for $\sigma_{Y}^{2}=0.25$ and 4.0 , and (e) and (f) drawdown distribution for $\sigma_{Y}^{2}=0.25$ and 4.0. A noteworthy feature of Figures $9 \mathrm{c}$ and $9 \mathrm{~d}$ is the very small range of $T_{\text {est }}$ values, suggesting that $T$ estimates in this field are independent of the location of the observation points.

ent locations. However, the applicability of these findings to real field data will strongly depend on several factors frequently encountered in field situations. These factors include, among others, skin effects due to well drilling and development, well losses, well bore storage effects, and delayed drainage.

\subsection{Test Case 4: Nonmultilognormal Field, Effect of $\boldsymbol{\sigma}_{Y}^{2}$}

Test cases 1-3 show that Jacob's method yields values very close to $T_{g}$ and $T_{\text {effp }}$ when applied to pumping test data from multilognormal $T$ fields. The objective of this test case is to 

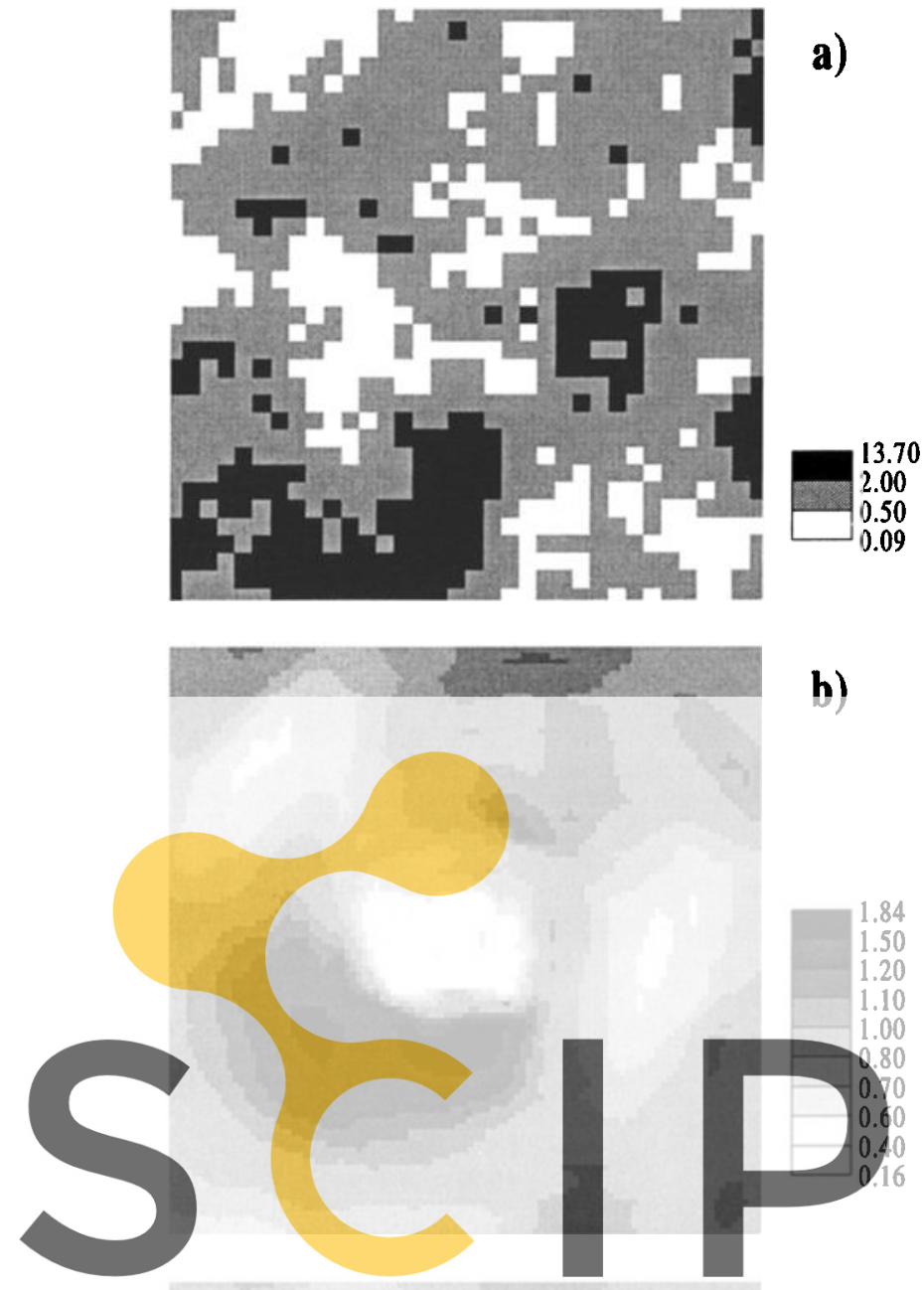

Register for free at https//www.scipedia.com to
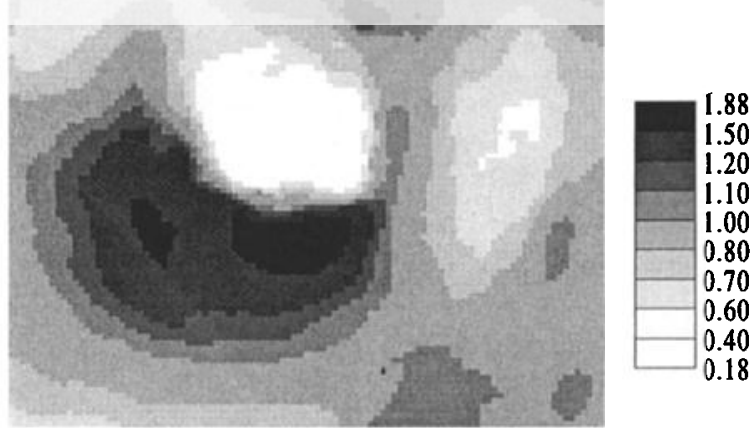

Figure 10. Test case $2:$ (a) subdomain $(100 \times 100$ units $)$ with increased support scale ( $T$ blocks of $3 \times 3$ units) and with the geostatistical parameters of test case 1, (b) spatial distribution of $S_{\text {est }}$ for test case 2, and (c) spatial distribution of $S_{\text {est }}$ for test case 1 with original support scale ( $T$ blocks of $1 \times 1$ units) and $\sigma_{Y}^{2}=1.0$.

extend our study to nonmultilognormal $T$ fields. For this purpose, we use field number 4 of Sánchez-Vila et al. [1996]. This field is shown in Figure 12a. It was generated by connecting high $T$ values of an originally multilognormal field while maintaining the histogram for the In $T$ field and the normality of the univariate distribution of $T$ values. The variogram and the multilognormality of the original field were not retained. The generation procedure is explained by Sánchez-Vila et al. [1996]. We believe that nonmultilognormal $T$ fields like the one shown in Figure 12a, having well-connected high $T$ zones, are better conceptual models for fractured rocks or alluvial aquifers than multilognormal $T$ fields. Sánchez-Vila et al. [1996] have shown that $T_{\text {effp }}$ may depend on $\sigma_{Y}^{2}$ in nonmultilognormal $T$ fields. Here we examine whether the good agreement between $T_{\text {effp }}$ and $T_{\text {avg }}$ obtained for multilognormal $T$ fields holds also for nonmultilognormal $T$ fields.

Radial flow was simulated in three $T$ fields with $\langle Y\rangle=0.0$ and $\sigma_{Y}^{2}$ values of 1.0, 2.1, and 4.1. The spatial $T_{\text {est }}$ distributions are shown in Figures $12 \mathrm{c}, 12 \mathrm{e}$, and $12 \mathrm{f}$. Note that the radial trend of the $T_{\text {est }}$ distributions, which is similar to the ones observed for test cases 1-3, may be attributed to applying Jacob's method over the same time range for all observation points, regardless of the distance to the pumping well.

Table 1 shows that $T_{\text {avg }}$ agrees well with $T_{\text {effp }}$ but is quite different from $T_{g}$ at large $\sigma_{Y \text {. }}^{2}$ These results indicate that performing a pumping test and using the slope of the drawdown curve in the analysis allow a value of transmissivity to be obtained that is very close to the effective transmissivity of the area influenced by the test, regardless of whether the $T$ field is multilognormal. We have observed this type of behavior on several occasions. The most dramatic is the one reported by Carrera et al. [1990], who found $T$ derived from a long-term pumping test to be 20 times larger than the geometric average of short-term single-hole tests performed
dium at mine wells at the Chalk River site i
highty transmissive channels as conceptua
are frequently observed within fractured
lead to the conclusion that tromsmissivities term pumping tests are frequently larger than those derived from the geometric mean of short-term single-hole tests (see

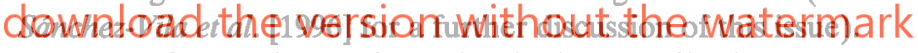
The main finding from this section is that an effective transmissivity for parallel flow is that obtained from long-term. pumping tests, rather than the geometric average of local values.

The spatial $S_{\text {est }}$ distribution is shown for $\sigma_{Y}^{2}=1.0$ in Figure 12d. Unlike the other test cases, it is difficult to recognize here a correlation between the input $T$ field and the spatial $S_{\text {est }}$ distribution. The fine structure of the input $T$ field is not reflected by the $S_{\text {est }}$ distribution, which seems to be the result of a spatial integration. Therefore we conjecture that $S_{\text {est }}$ depends not only on the nature of the connection between the well and the observation points but also on all the $Y$ values in a certain catchment area surrounding both the well and the observation points. This aspect is further explored by $X$. Sánchez-Vila et al. (Pumping tests in heterogeneous auquifers: An analytical study of what can be really obtained from their interpretation using Jacob's method, submitted to Water Resources Research, 1998). Note that the spatial $S_{\text {est }}$ distributions for the other $\sigma_{Y}^{2}$ qualitatively resemble the one shown in Figure $12 \mathrm{~d}$ and are therefore not presented.

\subsection{Test Case 5: Fractal Field}

A $\log$ transmissivity field was generated having a power law semivariogram $\gamma(h)=c h^{2 \omega}$ with $\omega=0.25$ and $c=0.027$, as proposed by Neuman [1990, 1994]. This $T$ field, shown in Figure 13a, is generated by conditioning on the transmissivity 



d)


f)

Figure 11. Test case 3: (a) and (b) Subdomains for $T$ fields with $T_{w}=0.61$ and $1.65\left(\sigma_{Y}^{2}=1.0\right)$ (the pumping well locations are in the center of the subdomain), (c) and (d) spatial distributions of $S_{\text {est }}$ for $T_{w}=$ 0.61 and 1.65, and (e) and (f) spatial distributions of $T_{\text {est }}$ for $T_{w}=0.61$ and 1.65.

value $\left(T_{w}=1.0\right)$ at the well. The field has a sample mean $\langle Y\rangle=-0.03$ and a sample variance $\sigma_{Y}^{2}=0.74$.

The spatial $T_{\text {est }}$ distribution, shown in Figure 13c, may be affected by the spatial distribution of the extreme transmissivity values which are located at the corners of the large domain, as the radial pattern observed in test cases $1-4$ is distorted. In this case, the original $T$ field is markedly nonstationary. Hence it is not surprising that some trend can be observed in $T_{\text {est }}$. However, the range of $T_{\text {est }}$ is relatively small. The fact that $T_{\text {avg }}>T_{g}>T_{\text {effp }}$ (see Table 1) may indicate a problem for the definition of an effective $T$ value for our fractal field. According to the relation given by Neuman [1994], $T_{\text {eff }}(L)=$ $T_{g} \exp \left(c L^{2 \omega}[0.5-\beta / E]\right)$, where $L$ is the characteristic length of a rock volume which acts as the support for a per- 

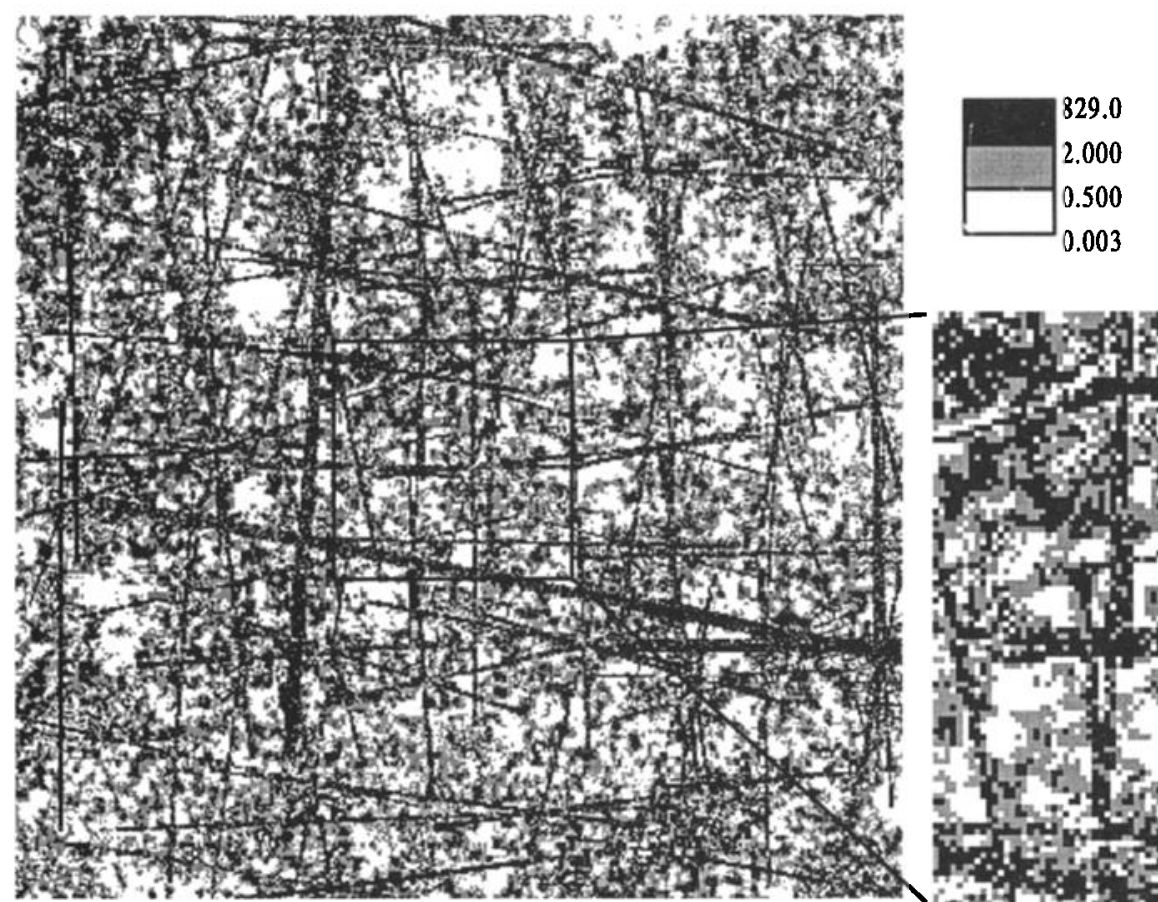

a)
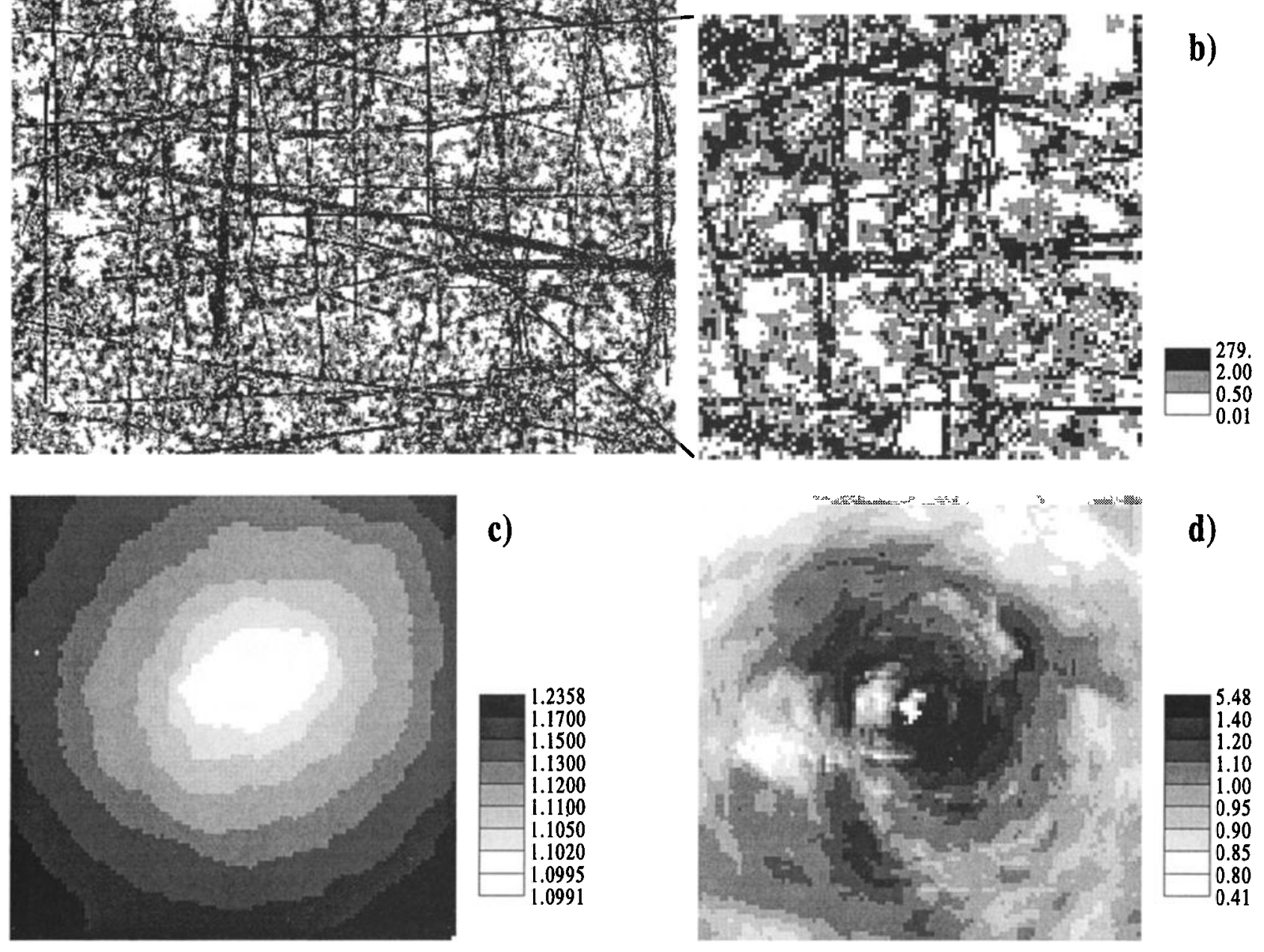

d)
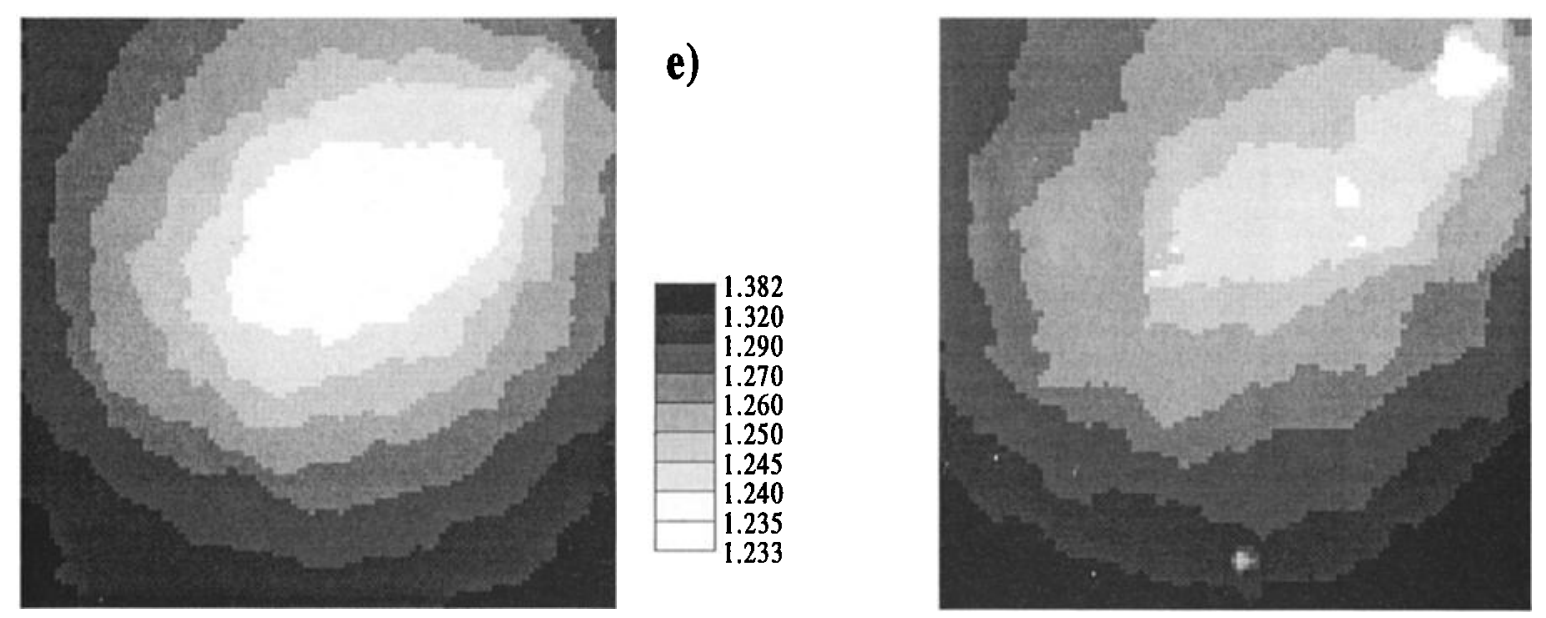

f)

Figure 12. Test case 4: (a) nonmultilognormal random $T$ field with $\sigma_{Y}^{2}=1.0(500 \times 500$ units), (b) subdomain $\left(100 \times 100\right.$ units) for which our methodology is considered valid, (c) spatial distribution of $T_{\text {est }}$ for $\sigma_{Y}^{2}=1.0$, (d) spatial distribution of $S_{\text {est }}$ for $\sigma_{Y}^{2}=1.0$, and (e) and (f) spatial distribution of $T_{\text {est }}$ for $\sigma_{Y}^{2}=$ 2.1 and 4.1 . 


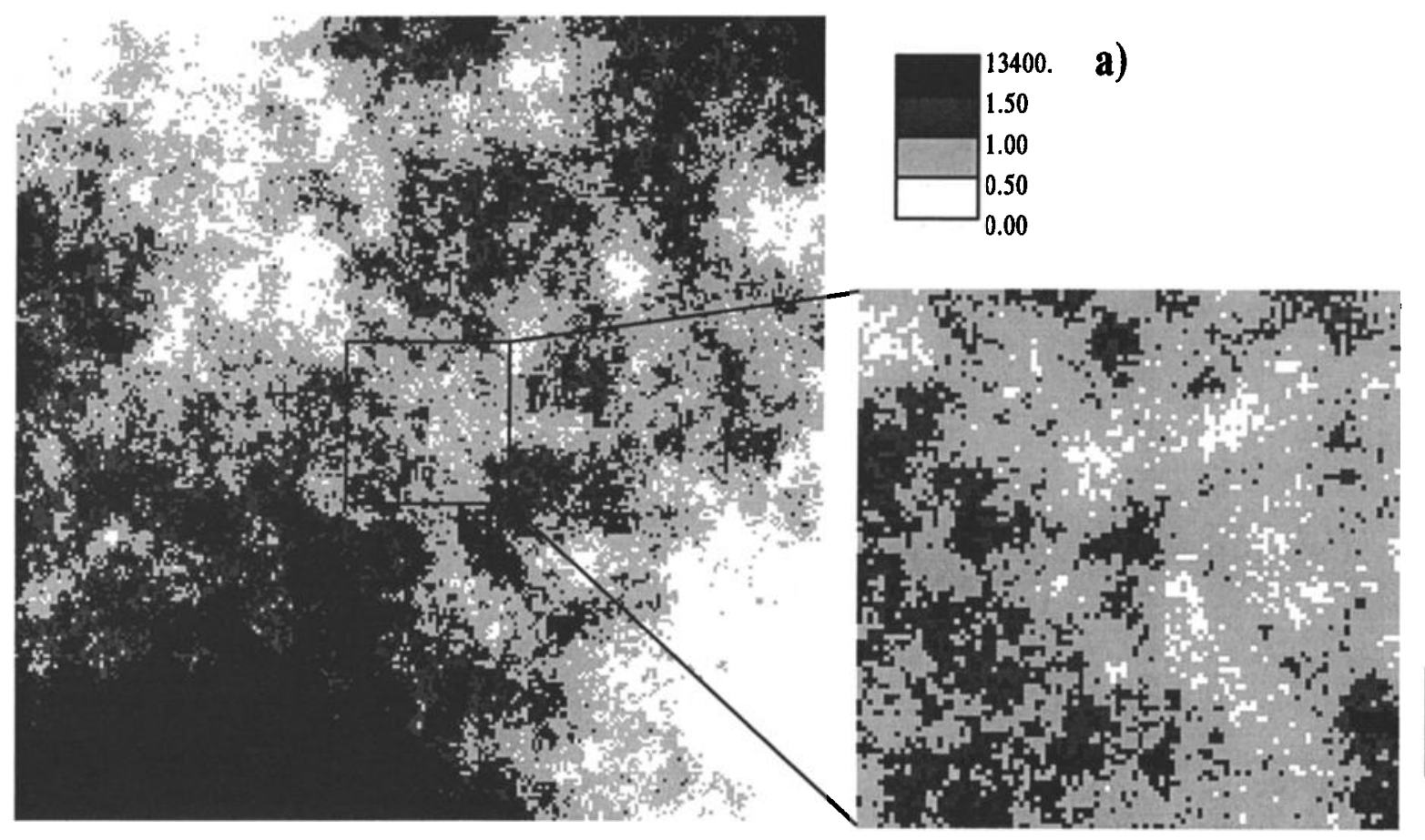

b)
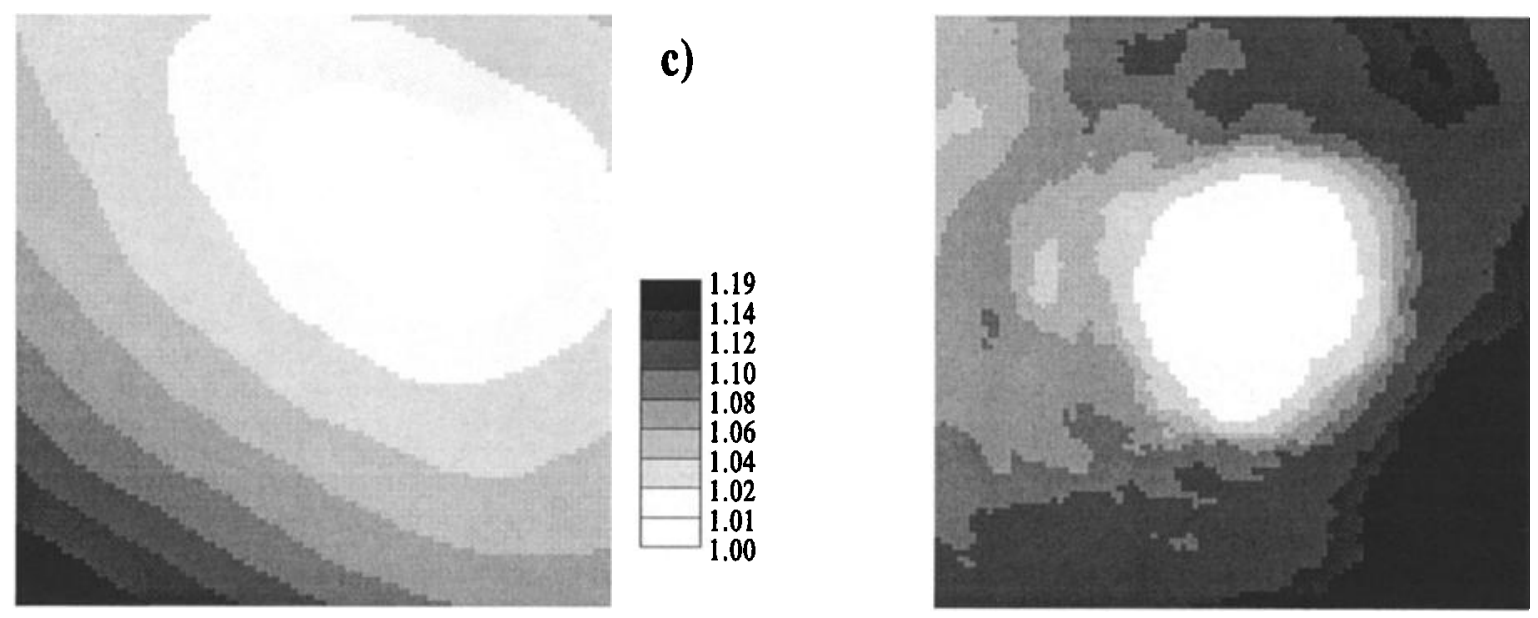

d)

Figure 13. Test case 5: (a) fractal $T$ field of $500 \times 500$ units, (b) subdomain $(100 \times 100$ units) for which our methodology is considered valid, (c) spatial distribution of $T_{\text {est }}$, and (d) spatial distribution of $S_{\text {est* }}$

meability test, $E$ is the dimension of the flow condition $(1,2$, or 3$)$, and $\beta=1$ for infinite isotropic media, $0 \leq \beta \leq 1$ for bounded isotropic media, and $1 \leq \beta \leq E$ for infinite anisotropic media. Using the above relation with our $T_{\text {avg, }}$, $T_{\text {effp }}, T_{g}$, and $L=700$ unit lengths, we obtain $\beta=0.82$ for $T_{\mathrm{avg}}$, indicating a bounded isotropic medium, and $\beta>1.0$ for $T_{\text {effp }}$, indicating an anisotropic medium. Inspection of Figure 13a reveals the somewhat anisotropic nature of this field. However, because the well is located at the center of the field and the extreme $T$ values are concentrated at the corners, the drawdown behavior is similar to the one for a bounded domain. The high $T$ zones at the bottom left and the top right corners act similar to constant head boundaries, whereas the low $T$ zones at the other corners act similar to no-flow boundaries.

The spatial distribution of $S_{\text {est }}$ (Figure 13d) seems to be dominated by the heterogeneities of the small domain pre- sented in Figure 13b. High $S_{\text {est }}$ correspond to zones with a low connectivity to the well, for example, the bottom right corners of Figures 13b and 13d, and vice versa.

\section{Summary and Conclusions}

1. Our numerical simulations of pumping tests in aquifers with heterogeneous transmissivity $T$ and homogeneous storativity $S$ show that applying Jacob's method to late time drawdown data at observation points results in a strong spatial variability of storativity estimates $S_{\text {est }}$ and in an almost homogeneous spatial distribution of transmissivity estimates $T_{\text {est }}$. This is in agreement with field observations.

2. Our simulations indicate that $S_{\text {est }}$ depends mainly on the connectivity between the well and the observation points. This was suggested by Schad and Teutsch [1994] on the basis of field observations and is consistent with the discussions of Butler 
[1990] and Butler and Liu [1993]. Furthermore, $S_{\text {est }}$ values seem to depend also on the transmissivities within a certain catchment area surrounding both the well and the observation points.

3. As has been shown in previous investigations, nonuniformities near the well have no effect on $T_{\text {est }}$. However, $S_{\text {est }}$ values vary considerably in the near-well region. A well located within a zone of $T>T_{\text {est }}$ results in $S_{\text {est }}$ values considerably greater than the formation $S$ and vice versa. This result has been documented in the petroleum engineering and groundwater literature [e.g., Barker and Herbert, 1982; Butler, 1988, 1990]. However, these results were mostly considered within the context of artificially induced heterogeneities around a well (e.g., skin effects due to drilling and development). We conjecture that these results could potentially be used to characterize natural small-scale heterogeneity (still much larger than the well radius), using $S_{\text {est }}$ values from single-hole pumping tests at different locations, provided that artificially induced heterogeneities at the well are either measured by other means or are negligible in comparison with natural small-scale heterogeneity.

4. $T_{\text {est }}$ values show an almost homogeneous spatial distribution for stationary input $T$ fields. The smooth radial trend of the $T_{\text {est }}$ distributions obtained for all test cases may largely be attributed to applying Jacob's method over the same time range for all observation points, regardless of the distance to the pumping well. However, in the case of the fractal $T$ field the spatial distribution of $T_{\text {est }}$ may also be affected by the spatial trend of the input $T$ field, although the enormous transmissivity contrasts of the input field are smoothed out dramatically. Furthermore, the arithmetic average of the $T_{\text {est }}$ values does not coincide with the effective transmissivity for parallel flow conditions in the fractal field $\left(T_{\text {effp }} / T_{\text {avg }}=0.9\right)$, although it should be noted that the concept of effective transmissivity is only valid for stationary fields.

5. Transmissivity estimates obtained from Jacob's method under radial flow conditions are close to the effective transmissivity for parallel flow conditions for the area of influence of the pumping test in multilognormal and nonmultilognormal $T$ fields. We consider nonmultilognormal $T$ fields, with wellconnected zones of relatively high $T$, to be realistic conceptual models for many, if not most, heterogeneous formations. Therefore the above conclusion bears two significant implications. First, Jacob's method does indeed work very well in most heterogeneous formations. Second, the problem that a single effective transmissivity value depending only on the statistical properties of a $T$ field cannot be derived for radial flow conditions does not affect the pumping test interpretation. Jacob's method directly provides a representative transmissivity which can be used for most hydrogeological problems dealing with parallel flow.

6. Our numerical work is based on the assumption of twodimensional and confined flow conditions and might therefore idealize complexities associated with field tests, especially in unconfined aquifers. Three-dimensional flow conditions might also be of concern in cases where the aquifer thickness is of a similar magnitude to the distance between the pumping well and the observation wells. The importance of such effects should be investigated in further studies.

Acknowledgments. Comments by G. Teutsch of the University of Tübingen, S. Young of Hydrogeologic Inc., and J. J. Butler of the
Kansas Geological Survey have helped improve the final text and are gratefully acknowledged. The first author acknowledges financial support from SATW (Swiss Academy of Engineering Sciences) and Nagra (Swiss National Cooperative for the Disposal of Radioactive Waste). The work of the remaining authors was funded by ENRESA (Spanish Nuclear Waste Management Company), 1995SGR00405 (CIRIT), and AMB95-0407 (CICYT). The data from the Grimsel test site were kindly supplied by Nagra and PNC (Power Reactor and Nuclear Fuel Development Corporation, Japan).

\section{References}

Bachu, S., and J. R. Underschulz, Regional scale porosity and permeability variations, Peace River Arch area, Alberta, Canada, $A A P G$ Bull., 76(4), 547-562, 1992.

Barker, J. A., A generalized radial flow model for hydraulic tests in fractured rock, Water Resour. Res., 24(10), 1796-1804, 1988.

Barker, J. A., and R. Herbert, Pumping tests in patchy aquifers, Ground Water, 20(2), 150-155, 1982.

Benet, I., and J. Carrera, A code for statistical interpretation of tracer tests, in Proceedings of the 6th Intemational Symposium on Water Tracing, edited by H. Hotzl and A. Werner, pp. 457-460, A. A. Balkema, Brookfield, Vt., 1992.

Bureau de Recherches Géologiques et Minières, Interpretation of hydraulic tests (pulse tests, slug tests and pumping tests) from the third testing campaign at the El Cabril site (Spain) (in French), technical report for Spanish Nuclear Waste Management Company, Orléans, France, 1990.

Butler, J. J., Jr., Pumping tests in nonuniform aquifers: The radially symmetric case, J. Hydrol., 101, 15-30, 1988.

Butler, J. J., Jr., The role of pumping tests in site characterization: Some theoretical considerations, Ground Water, 28(3), 394-402, 1990.

Butler, J. J., Jr., A stochastic analysis of pumping tests in laterally nonuniform media, Water Resour. Res., 27(9), 2401-2414, 1991.

Butler, J. J., Jr., and W. Z. Liu, Pumping tests in non-uniform aquifers-The linear strip case, J. Hydrol., 128, 69-99, 1991.

Butler, J. J., Jr., and W. Z. Liu, Pumping tests in nonuniform aquifers: The radially asymmetric case, Water Resour. Res., 29(2), 259-269, 1993.

Carbonell, J. A., and J. Carrera, MARIAJ code for the automatic interpretation of pumping tests, user's manual, Polytech. Univ. of Catalunya, Barcelona, Spain, 1992.

Carrera, J., An overview of uncertainties in modeling groundwater solute transport, J. Contam. Hydrol., 13, 23-48, 1993.

Carrera, J., and S. P. Neuman, Estimation of aquifer parameters under transient and steady state conditions, 1, Maximum likelihood method incorporating prior information, Water Resour. Res., 22(2), 199-210, 1986.

Carrera, J., J. Heredia, S. Vomvoris, and P. Hufschmied, Modeling of flow on a small fractured monzonitic gneiss block, in Hydrogeology of Low Permeability Environments, Hydrogeol. Selec. Pap., vol. 2, edited by S. P. Neuman and I. Neretniks, pp. 115-169, Int. Assoc. of Hydrogeol., Kenilworth, England, 1990.

Carrera, J., X. Sánchez-Vila, J. Samper, F. J. Elorza, J. Heredia, J. A. Carbonell, and C. Bajos, Radioactive waste disposal on a highly heterogeneous fracture medium, 1 , Conceptual models of groundwater flow, in Proceedings of the International Association of Hydrogeologists, XXIVth Congress, Hydrogeology of Hard Rocks, edited by S. B. Banks and D. Banks, vol. 1, pp. 190-202, Geol. Surv. of Norway, Trondheim, 1993.

Cooper, H. H., Jr., and C. E. Jacob, A generalized graphical method for evaluating formation constants and summarizing well-field history, Eos Trans. $A G U, 27(4), 526-534,1946$.

de Marsily, G., Quantitative Hydrogeology, Groundwater Hydrology for Engineers, 440 pp., Academic, San Diego, Calif., 1986.

Earlougher, R. C., Jr., Advances in Well Test Analysis, Henry L. Doherty Monogr. Ser., vol. 5, 264 pp., Soc. of Pet. Eng., Dallas, Tex., 1977.

Freeze, R. A., and J. A. Cherry, Groundwater, 604 pp., Prentice-Hall, Englewood Cliffs, N. J., 1979.

Frick, U., et al., Grimsel test site, The Radionuclide Migration Experiment-Overview of investigations 1985-1990, Nagra Tech. Rep. 91 04, Nagra, Wettingen, Switzerland, 1992.

Gómez-Hernández, J. J., and A. G. Journel, Joint sequential simulation of multiGaussian fields, in Geostatistics Trója '92, vol. 1, edited by A. Soares, pp. 85-94, Kluwer Acad., Norwell, Mass., 1993. 
Gómez-Hernández, J. J., H. Sovero, and A. Sahuquillo, Some issues on the analysis of pumping tests in heterogeneous aquifers, Hydrogeol., 3, 13-18, 1995.

Guimerà, J., and J. Carrera, On the interdependence of transport and hydraulic parameters in low permeability fractured media, in Hard Rock Hydrosystems, pp. 123-133, LAHS Publ., 241, 1997.

Hantush, M. S., Analysis of data from pumping tests in anisotropic aquifers, J. Geophys. Res., 71(2), 421-426, 1966.

Herweijer, J. C., Constraining uncertainty of groundwater flow and transport models using pumping tests, in Calibration and Reliability in Groundwater Modelling, IAHS Publ., 237, 473-482, 1996.

Herweijer, J. C., and S. C. Young, Use of detailed sedimentological information for the assessment of aquifer tests and tracer tests in a shallow fluvial aquifer, in Proceedings of the 5th Annual Canadian/ American Conference on Hydrogeology: Parameter Identification and Estimation for Aquifer and Reservoir Characterization, pp. 101-115, Natl. Water Well Assoc., Dublin, Ohio, 1991.

Lachassagne, P., E. Ledoux, and G. de Marsily, Evaluation of hydrogeological parameters in heterogeneous porous media, in Groundwater Management: Quantity and Quality, LAHS Publ., 188, 3-18, 1989.

Matheron, G., Elements pour une Theorie des Milieux Poreux, 166 pp., Masson et Cie, Paris; 1967.

Meier, P. M., GTS: Migration Experiment (MI) and Radionuclide Retardation Project (RRP), Results of additional hydraulic testing in the migration shear-zone, Nagra Internal Rep. 96-37, Nagra, Wettingen, Switzerland, 1997.

Meier, P. M., J. Carrera, A. Medina, and L. Vives, Inverse geostatistical modeling of ground water flow within a shear-zone in granite, in Proceedings of IAMG 1997, the Third Annual Conference of the International Association for Mathematical Geology, vol. 2, edited by V. Pawlowsky-Glahn, pp. 755-760, Int. Cent. of Numer. Method in Eng., Barcelona, Spain, 1997.

Neuman, S. P., Universal scaling of hydraulic conductivities and dispersivities in geologic media, Water Resour. Res., 26(8), 1749-1758, 1990.

Neuman, S. P., Generalized scaling of permeabilities: Validation and effect of support scale, Geophys. Res. Lett., 21(5), 349-352, 1994.

Neuman, S. P., G. R. Walter, H. W. Bentley, J. J. Ward, and D. D. Gonzales, Determination of horizontal aquifer anisotropy with three wells, Ground Water, 22(1), 66-72, 1984.
Neuzil, C. E., How permeable are clays and shales?, Water Resour. Res., 30(2), 145-150, 1994.

Oliver, D. S., The averaging process in permeability estimation from well-test data, SPE Form. Eval., 5, 319-324, 1990.

Oliver, D. S., The influence of nonuniform transmissivity and storativity on drawdown, Water Resour. Res., 29(1), 169-178, 1993.

Papadopulos, I. S., Nonsteady flow to a well in an infinite anisotropic aquifer, in Proceedings of the Dubrovnik Symposium on the Hydrology of Fractured Rocks, pp. 21-31, Int. Assoc. of Hydrol. Sci., Washington, D. C., 1965.

Ptak, T., and G. Teutsch, A comparison of investigation methods for the prediction of flow and transport in highly heterogeneous formations, in Transport and Reactive Processes in Aquifers, edited by T. Dracos and F. Stauffer, A. A. Balkema, Brookfield, Vt., 1994.

Sánchez-Vila, X., J. Carrera, and I. Colominas, Directional effects on convergent flow tracer tests, in Proceedings of the 6th International Symposium on Water Tracing, edited by $\mathrm{H}$. Hotzl and A. Werner, pp. 407-414, A. A. Balkema, Brookfield, Vt., 1992.

Sánchez-Vila, X., J. Carrera, and J. P. Girardi, Scale effects in transmissivity, J. Hydrol., 183, 1-22, 1996.

Schad, H., and $\mathbf{G}$. Teutsch, Effects of the investigation scale on pumping test results in heterogeneous porous aquifers, J. Hydrol., 159, 61-77, 1994.

Streltsova, T. D., Well Testing in Heterogeneous Formations, 413 pp., John Wiley, New York, 1988.

Theis, C. V., The relation between the lowering of the piezometric surface and the rate and duration of discharge of a well using ground-water storage, Eos Trans. $A G U, 16,519-524,1935$.

Warren, J. E., and H. S. Price, Flow in heterogeneous media, Soc. Pet. Eng. J., 1, 153-169, 1961.

J. Carrera, P. M. Meier, and X. Sánchez-Vila, Department Enginyeria del Terreny i Cartogràfica, E. T. S. Enginyers de Camins, Canals i Ports de Barcelona, Universitat Politècnica de Catalunya, Modul D-2, 08034 Barcelona, Spain. (e-mail: carrera@etseccpb.upc.es; vmeiers@etseccpb.upc.es; dsanchez@etseccpb.upc.es)

(Received December 31, 1996; revised December 23, 1997; accepted December 29, 1997.) 